\title{
COLOMBIA: PAÍS DEL AÑo 2016
}

\author{
Colombia: Country of the Year 2016
}

\section{JUAN CARLOS RODRÍGUEZ-RAGA*}

Universidad de los Andes, Colombia

\begin{abstract}
RESUMEN
El objetivo de este artículo es reseñar los eventos más importantes del entorno político en Colombia durante 2016. El énfasis de este resumen del año está en los hechos y procesos que condujeron a la firma del acuerdo de paz entre el gobierno de Juan Manuel Santos y las Fuerzas Armadas Revolucionarias de Colombia (FARC). La primera sección describe cómo fue el camino hacia la firma del primer acuerdo en agosto, rastrea el proceso de refrendación mediante un plebiscito popular en octubre, y analiza los impactos que tuvo la victoria de quienes se oponían al acuerdo sobre el proceso de negociación y sobre el gobierno mismo. La segunda sección muestra cómo algunas actitudes de confianza ciudadana hacia las instituciones se han deteriorado en los últimos años y relaciona dicho clima de la opinión con el fenómeno de polarización entre los seguidores del expresidente Álvaro Uribe y las demás personas. La tercera sección reseña cómo la economía, durante 2016, sufrió una desaceleración moderada en términos comparativos con el resto de América Latina. En la cuarta parte se analiza la composición del gobierno y su gabinete, y en la quinta se hace una relación de la producción legislativa durante este año. El artículo cierra con unas breves conclusiones sobre cómo el resultado del plebiscito constituyó un golpe anticlimático para el esperado fin del conflicto con la guerrilla más antigua del mundo.
\end{abstract}

Palabras clave: Colombia, FARC, conflicto armado, acuerdo de paz, plebiscito

\begin{abstract}
This article reviews the most important events in the Colombian political arena during 2016. The focus of this review is on the facts and processes that led to the signature of the peace agreement between the national government led by Juan Manuel Santos and the Fuerzas Armadas Revolucionarias de Colombia (FARC). The first section describes the road towards the signing of the first agreement in August, tracks the process of popular ratification of the agreement through a plebiscite in October, and analyzes the impact of the victory of the opposition to the agreement on the peace talks, and on the administration itself. The second section shows how some attitudes related to public trust in institutions have deteriorated in the past few years and states how these attitudes might be related to a sharp polarization between those who follow former president Álvaro Uribe and those who do not. The third section reviews the moderate economic slowdown as compared to other countries in Latin America. In the fourth section I analyze the composition of Santos's cabinet, and in the fifth I show the legislative agenda during the year. The article closes with some brief conclusions on how the plebiscite's results became an anti-climactic blow to the much-awaited end of the conflict with the oldest guerrilla group in the world.
\end{abstract}

Key words: Colombia, FARC, armed conflict, peace agreement, plebiscite

Agradezco el apoyo del equipo del Observatorio de la Democracia en la graficación de los resultados del Barómetro de las Américas que ilustran algunas secciones de este artículo. Agradezco también los comentarios de los referees que sin duda contribuyeron a mejorar la versión final del mismo. 


\section{INTRODUCCIÓN}

A fines de diciembre de 2016, la revista inglesa The Economist declaró a Colombia como país del año. La publicación, que otorga anualmente este reconocimiento al país que, a su entender, logró los avances más significativos durante los doce meses anteriores, justificó su selección simplemente con esta frase: "por hacer la paz en 2016" (The Economist 2016, 24 de diciembre).

Sin duda, la firma del acuerdo de paz entre el gobierno colombiano y la guerrilla de las FARC no solo fue el mayor logro del país en el año sino probablemente el hecho más importante de las últimas décadas. Veinticinco años después de promulgada la Constitución de 1991 que, en su momento, se concibió como un pacto de paz (Dugas 1993; Gutiérrez 2011), en 2016 se cerraron cuatro años de negociaciones en La Habana y se puso fin a un conflicto que duró más de medio siglo y costó cerca de 220.000 vidas (Centro Nacional de Memoria Histórica 2017). El proceso de negociación y la firma del acuerdo, además, significaron el premio Nobel de la Paz para el presidente Juan Manuel Santos.

Este hecho histórico, sin embargo, no significó para el país que el año cerrara con un clima de euforia ni mucho menos constituyó para el gobierno un año idílico; todo lo contrario. Aunque para el caso colombiano hablar de un año turbulento es casi redundante, en 2016 la turbulencia se sintió ya no por la violencia política sino principalmente por la polarización, cada vez más acentuada, entre los detractores del acuerdo de paz y quienes lo respaldan, entre el campo uribista y los sectores más cercanos al gobierno y al proceso. La crispación alcanzó su máxima expresión en la campaña para el plebiscito que buscaba refrendar el acuerdo, cuyo resultado, a pesar de la terminación del conflicto armado interno más prolongado del mundo, dejó al final del año un sabor anticlimático que dificulta ver con optimismo los años que vienen. El país no logró recuperar el entusiasmo ni aun con las desmovilizaciones masivas de los diferentes frentes de las FARC a las zonas de concentración que se iniciaron en enero de 2017.

Este balance del año 2016 en Colombia presenta, en primer lugar, una cronología del final del proceso de paz, la firma del acuerdo, su fallida refrendación y la posterior renegociación y nueva firma. En segundo lugar, se analiza el clima de la opinión pública frente a las instituciones políticas y el sistema democrático. La tercera sección, por su parte, se ocupa de resumir el desempeño de la economía colombiana. Las secciones cuarta y quinta, finalmente, describen la estructura del gabinete ministerial del gobierno Santos y la producción legislativa del Congreso de la República, respectivamente.

\section{EL CAMINO FINAL HACIA LA PAZ CON LAS FARC}

El 3 de septiembre de 2012, tras más de un año de conversaciones secretas, el presidente Santos dio inicio a la fase pública de la negociación con las FARC. Este anuncio resultó altamente sorpresivo para el país habida cuenta del hecho 
de que Juan Manuel Santos había sido elegido presidente en 2010 como heredero natural y con el manifiesto apoyo del presidente saliente, Álvaro Uribe, de cuyo gobierno había sido ministro de Defensa. El marcado contraste con el gobierno anterior, cuyo tratamiento del conflicto con la guerrilla durante sus dos períodos (2002-2006 y 2006-2010) había sido de confrontación y mano dura mediante la llamada "política de seguridad democrática", suponía, al menos en apariencia, un abrupto cambio de rumbo en el manejo del orden público y del conflicto con la guerrilla de las FARC.

En realidad, los acercamientos secretos se habían iniciado al final del segundo período de Uribe. Aunque se habían visto interrumpidos en plena campaña electoral de 2010, en el período de empalme que se dio entre la elección y la posesión de Santos, este mostró un decidido interés en reanudar estas conversaciones secretas (Semana 2012, 1 de septiembre). En febrero de 2012 se produjo en La Habana el primero de numerosos encuentros entre equipos negociadores de ambas partes (Semana 2017, 24 de febrero; Santos Calderón 2014), al cabo de los cuales se llegó al anuncio del Acuerdo General en septiembre de ese año.

Dicho acuerdo marco, además de fijarse reglas procedimentales que incluían la discreción, la negociación en medio de la guerra y la integralidad de lo convenido, ${ }^{1}$ contenía los seis puntos de la agenda sobre los que, durante los cuatro años siguientes, se centrarían los diálogos y que serían los puntos consignados en el Acuerdo Final (Gobierno Nacional y FARC-EP 2012). Estos puntos son los siguientes: (1) Reforma rural integral; (2) Participación política; (3) Fin del conflicto (cese al fuego, dejación de armas, etc.); (4) Drogas ilícitas; (5) Acuerdo sobre víctimas, incluyendo la Justicia Especial de Paz; (6) Protocolos y mecanismos de implementación, verificación y refrendación.

De estos puntos, tres concernían directamente la mecánica del proceso de paz y mecanismos de justicia transicional (puntos 3, 5 y 6) y otros tres estaban relacionados con reformas que, en principio, buscaban solucionar condiciones que alimentaban el conflicto (puntos 1,2 y 4 ). ${ }^{2}$

El año 2016 empezó con dos buenos augurios para el devenir del proceso de paz del gobierno con las FARC. Por un lado, se posesionaron las autoridades locales y regionales y los buenos resultados de los partidos cercanos al gobierno nacional en las elecciones de octubre de 2015 ofrecían un panorama favorable a la implementación de la llamada "paz territorial", esto es, la idea de que debían ponerse en marcha los diferentes componentes del acuerdo de abajo hacia arriba, de la periferia hacia el centro, desde los territorios más remotos, más afectados

1 Para ilustrar este punto, el gobierno acuñó la expresión "nada está acordado hasta que todo esté acordado". Ver, por ejemplo, la entrevista concedida por Santos al periodista y caricaturista Vladdo (Huffington Post 2013, 20 de abril).

2 Para consultar el texto completo del acuerdo final, ver Oficina del Alto Comisionado para la Paz (2016). 
por el conflicto y, en principio, más propensos a reproducir las condiciones que podrían poner en riesgo la paz.

Por otro lado, las conversaciones en La Habana entre los negociadores del gobierno y la guerrilla parecían avanzar con buen ritmo y se preveía que este sería el año del cierre de las negociaciones. Durante los años anteriores, en varios momentos las FARC habían decretado sucesivos ceses unilaterales del fuego y de hostilidades que, a pesar de los altibajos y recaídas, habían logrado disminuir los niveles de violencia asociada con el conflicto. Las conversaciones, por su parte, iban a buen ritmo y desde septiembre de 2015 se había fijado un plazo de seis meses para la firma del acuerdo final, es decir, en marzo de 2016. De hecho, antes de iniciar el 2016 ya se habían acordado los puntos 1 (mayo de 2013), 2 (agosto de 2013), 4 (mayo de 2014) y 5 (septiembre de 2015) del Acuerdo General anunciado en agosto de 2012. En enero de 2016 se anunció el acuerdo sobre la verificación del fin del conflicto, parte del punto 6 (Gobierno Nacional y FARC-EP 2016a).

\section{AVANCE DE LA NEGOCIACIÓN Y PRIMERA FIRMA}

Aunque el plazo de marzo no pudo cumplirse por diferencias en la discusión del punto 3 sobre fin del conflicto, las negociaciones siguieron avanzando durante el primer semestre y parte del segundo semestre. La Tabla 1 muestra los principales acuerdos a los que las partes llegaron durante estos meses, antes de la firma de la primera versión del Acuerdo Final. 
Tabla 1. Acuerdos firmados entre el Gobierno Nacional y las FARC entre enero y agosto de 2016

\begin{tabular}{|c|c|c|c|}
\hline Fecha & Acuerdo & Descripción/Objetivo & Fuente \\
\hline $\begin{array}{l}19 \text { de enero, } \\
2016\end{array}$ & $\begin{array}{l}\text { Acuerdo sobre } \\
\text { verificación del fin } \\
\text { del conflicto }\end{array}$ & $\begin{array}{l}\text { Complementa lo pactado en el punto } \\
6 \text { sobre implementación, verificación y } \\
\text { refrendación del acuerdo final. }\end{array}$ & $\begin{array}{l}\text { Gobierno Na- } \\
\text { cional \& FARC- } \\
\text { EP 2016b }\end{array}$ \\
\hline $\begin{array}{l}12 \text { de mayo, } \\
2016\end{array}$ & $\begin{array}{l}\text { Garantías jurídicas } \\
\text { para el acuerdo } \\
\text { final }\end{array}$ & $\begin{array}{l}\text { Busca incorporar el texto del acuerdo } \\
\text { final al marco jurídico-constitucional } \\
\text { del país como un Acuerdo Especial, con } \\
\text { arreglo a los Convenios de Ginebra, con } \\
\text { el fin de dar garantías para su cumpli- } \\
\text { miento. }\end{array}$ & $\begin{array}{l}\text { Gobierno Na- } \\
\text { cional \& FARC- } \\
\text { EP 2016c }\end{array}$ \\
\hline $\begin{array}{l}23 \text { de junio, } \\
2016\end{array}$ & $\begin{array}{l}\text { Cese bilateral al } \\
\text { fuego y dejación de } \\
\text { armas }\end{array}$ & $\begin{array}{l}\text { Establece el protocolo y calendario de } \\
\text { desmovilización y dejación de armas, } \\
\text { dentro del punto } 3 \text { de la agenda. }\end{array}$ & $\begin{array}{l}\text { Gobierno Na- } \\
\text { cional \& FARC- } \\
\text { EP 2016d }\end{array}$ \\
\hline $\begin{array}{l}5 \text { de julio, } \\
2016\end{array}$ & $\begin{array}{l}\text { Revisión del pun- } \\
\text { to } 2\end{array}$ & $\begin{array}{l}\text { Resuelve temas que habían quedado } \\
\text { pendientes del texto acordado del pun- } \\
\text { to } 2 \text { sobre participación política. }\end{array}$ & $\begin{array}{l}\text { Gobierno Na- } \\
\text { cional \& FARC- } \\
\text { EP 2016e }\end{array}$ \\
\hline $\begin{array}{l}24 \text { de julio, } \\
2016\end{array}$ & $\begin{array}{l}\text { Inclusión del enfo- } \\
\text { que de género }\end{array}$ & $\begin{array}{l}\text { La subcomisión de género presenta } \\
\text { su informe sobre la incorporación del } \\
\text { enfoque de género en los acuerdos. }\end{array}$ & $\begin{array}{l}\text { Gobierno Na- } \\
\text { cional \& FARC- } \\
\text { EP } 2016 f\end{array}$ \\
\hline $\begin{array}{l}5 \text { de agosto, } \\
2016\end{array}$ & $\begin{array}{l}\text { Protocolos sobre } \\
\text { cese al fuego y deja- } \\
\text { ción de armas }\end{array}$ & $\begin{array}{l}\text { Se detallan los protocolos y mecanis- } \\
\text { mos para el fin del conflicto y su veri- } \\
\text { ficación. }\end{array}$ & $\begin{array}{l}\text { Gobierno Na- } \\
\text { cional \& FARC- } \\
\text { EP } 2016 \mathrm{~g}\end{array}$ \\
\hline $\begin{array}{l}12 \text { de agosto, } \\
2016\end{array}$ & $\begin{array}{l}\text { Acuerdo sobre } \\
\text { mecanismo de } \\
\text { selección de magis- } \\
\text { trados de la JEP }\end{array}$ & $\begin{array}{l}\text { Definición de la forma como serán } \\
\text { elegidos los magistrados y magistradas } \\
\text { que harán parte del tribunal de la Justi- } \\
\text { cia Especial para la Paz }\end{array}$ & $\begin{array}{l}\text { Gobierno Na- } \\
\text { cional \& FARC- } \\
\text { EP 2016h }\end{array}$ \\
\hline
\end{tabular}

Fuente: elaboración propia.

De forma paralela al avance de las negociaciones en La Habana, el gobierno lograba triunfos políticos y jurídicos en relación con diferentes elementos del proceso como los que se resumen en la Tabla 2. 
Tabla 2. Triunfos políticos y jurídicos del gobierno previos a la firma

\begin{tabular}{|c|c|c|c|}
\hline Fecha & Escenario/Actor & Descripción & Fuente \\
\hline $\begin{array}{l}23 \text { de febrero, } \\
2016\end{array}$ & Partidos políticos & $\begin{array}{l}\text { Pacto por la Paz entre el gobierno y } \\
\text { gran parte de los partidos y movimien- } \\
\text { tos políticos con el fin de brindar un } \\
\text { respaldo a la etapa final de la negocia- } \\
\text { ción. }\end{array}$ & $\begin{array}{l}\text { Presidencia de } \\
\text { la República } \\
2016\end{array}$ \\
\hline $\begin{array}{l}9 \text { de marzo, } \\
2016\end{array}$ & Congreso & $\begin{array}{l}\text { Aprobación de la reforma a la Ley de } \\
\text { Orden Público para permitir la crea- } \\
\text { ción de las zonas de concentración de } \\
\text { guerrilleros desmovilizados, y para } \\
\text { facultar al presidente para suspender } \\
\text { órdenes de captura para los miembros } \\
\text { de las FARC. }\end{array}$ & $\begin{array}{l}\text { El Heraldo } \\
2016,9 \text { de } \\
\text { marzo }\end{array}$ \\
\hline $\begin{array}{l}9 \text { de junio, } \\
2016\end{array}$ & Congreso & $\begin{array}{l}\text { Aprobación de reforma constitucional } \\
\text { que incorpora el acuerdo al bloque } \\
\text { de constitucionalidad como Acuerdo } \\
\text { Especial. }\end{array}$ & $\begin{array}{l}\text { El Espectador } \\
2016,9 \text { de } \\
\text { junio }\end{array}$ \\
\hline $\begin{array}{l}18 \text { de julio, } \\
2016\end{array}$ & $\begin{array}{l}\text { Corte Constitu- } \\
\text { cional }\end{array}$ & $\begin{array}{l}\text { Exequibilidad de la ley de convocatoria } \\
\text { del plebiscito para refrendar el acuer- } \\
\text { do; se avala el procedimiento de apro- } \\
\text { bación cuyas exigencias en cuanto al } \\
\text { nivel de participación ciudadana fue- } \\
\text { ron relajadas por la ley mencionada.* }\end{array}$ & $\begin{array}{l}\text { El Colombiano } \\
2016,18 \text { de } \\
\text { julio }\end{array}$ \\
\hline
\end{tabular}

Fuente: elaboración propia.

Desde 2013 el presidente Santos se había comprometido a que el acuerdo que se habría de firmar con las FARC sería sometido al voto popular. A pesar de ser una jugada arriesgada y jurídicamente innecesaria, el gobierno buscaba con la refrendación el blindaje político del acuerdo de tal manera que para algún gobierno futuro se elevaran los costos de desconocerlo. Aunque las FARC inicialmente no aprobaban esta forma de refrendación y durante mucho tiempo insistieron en la convocatoria a una Asamblea Constituyente, finalmente accedieron este mecanismo en junio de 2016 (Caracol 2016, 5 de junio). No está muy claro si el gobierno seguía convencido de la bondad de esta medida tres años después o si la presión de los opositores al acuerdo para que la promesa fuera cumplida le impidió desistir. Como se describe más adelante, el plebiscito se convirtió en un punto de inflexión dentro del proceso de paz y fue determinante para el debilitamiento del gobierno y el ambiente de anticlímax con que cerró el año 2016.

El 24 de agosto, Humberto de la Calle e Iván Márquez, jefes de las delegaciones del Gobierno y de las FARC, respectivamente, anuncian al país y al mundo desde La Habana que se ha llegado a un acuerdo final. Cuatro años después de divulgada la agenda, la firma de las dos partes evidenciaba, al menos por el momento, que la negociación sobre los seis puntos de la agenda fijada en 2012 había llegado a su fin (CNNE 2016, 24 de agosto; Gobierno Nacional y FARC-EP 2016i). La ceremonia fue transmitida en pantalla gigante en varios lugares públicos de la capital y de otras ciudades, y generó multitudinarias demostraciones de júbilo y celebración en las calles (Pacifista 2016).

Ese mismo día, el presidente informa al país que el acuerdo será refrendado el 2 de octubre siguiente mediante el plebiscito aprobado por el Congreso y avalado por la Corte Constitucional. Al día siguiente, Santos entrega al Congreso el acuerdo firmado por los jefes de las delegaciones y declara el cese al fuego 
bilateral y definitivo que entraría en vigor a partir del 29 de agosto, dando fin a la guerra con las FARC (CNNE 2016, 25 de agosto; Semana 201628 de agosto), y que, desde entonces, no ha sufrido ninguna violación seria.

\section{EL PLEBISCITO Y SUS CONSECUENCIAS}

Desde ese momento se inició formalmente la campaña de los promotores y de los opositores del acuerdo con las FARC por obtener el favor de los votantes.

La campaña por el No estaba liderada por el partido Centro Democrático encabezado por el expresidente y hoy senador Álvaro Uribe. Desde el inicio de la fase pública de conversaciones entre el gobierno y las FARC, Uribe y sus seguidores se habían convertido en los principales detractores del diálogo con esta guerrilla a la que siempre consideraron como un simple grupo terrorista al que no habría que hacerle ninguna concesión, con el que no se debería negociar y al que habría que someter militarmente para lograr su rendición.

A este grupo se sumaron eventualmente otras figuras y agrupaciones que constituyeron el bloque del No en el plebiscito. Por una parte, el expresidente Andrés Pastrana, quien durante su gobierno (1998-2002) había adelantado el último intento de negociación con las FARC cuyo fracaso explica en gran parte la elección en 2002 de Uribe con una bandera de mano dura con la guerrilla, se unió a Uribe en sus críticas al gobierno Santos. Junto con Martha Lucía Ramírez, excandidata presidencial, encabezó una disidencia del Partido Conservador en contra del acuerdo y los mecanismos para su implementación. ${ }^{3}$

En la campaña por el No también fue importante Alejandro Ordóñez, ex Procurador General de la Nación. ${ }^{4}$ Desde su paso por este órgano de control, Ordóñez, de orientación muy conservadora y declarada militancia católica radical, había formulado duras críticas al proceso. Junto con una agrupación de iglesias cristianas, hizo campaña por el No denunciando que el acuerdo firmado con las FARC promovía una supuesta "ideología de género" que atentaba contra los valores de la familia.

La estrategia de los opositores al gobierno en el plebiscito se centró principalmente en difundir a través de los medios de comunicación, de las redes sociales y de vallas instaladas en varias ciudades del país, imprecisiones e incluso falsedades con respecto al acuerdo firmado con las FARC. Además de capitalizar el conservadurismo de las personas más religiosas, cristianas y católicas (ante la pasividad pública de la jerarquía de la Iglesia Católica), esta campaña quedó

\footnotetext{
La bancada legislativa de este partido, aunque no hace formalmente parte de la Unidad Nacional, que es la coalición de gobierno, acompañó siempre el proceso y se sumó al campo del Sí en el plebiscito.

En septiembre, casi simultáneamente, se produjo la renuncia de Ordóñez a la Procuraduría y el fallo del Consejo de Estado que anulaba su reelección en ese cargo por haber nombrado durante su primer período (2009-2012) a familiares de magistrados de la Corte Suprema de Justicia que luego lo habrían de postular para dicha reelección (El Tiempo 2016, 23 de septiembre).
} 
al descubierto poco después del 2 de octubre cuando, en una entrevista con un medio escrito, Juan Carlos Vélez, gerente de la campaña del Centro Democrático por el No, se ufanó de haber atizado los temores y el resentimiento de la gente con la guerrilla de las FARC, en lugar de explicar y discutir el contenido del acuerdo (El Colombiano 2016, 6 de octubre).

El gobierno y quienes apoyaban el proceso de paz, por su parte, adelantaron una campaña concentrada en explicar los diferentes elementos del acuerdo, aunque también acudieron a despertar el temor de lo que podría suceder en términos de prolongación del conflicto y de aumento de la violencia en el caso de una eventual derrota en el plebiscito.

Aunque inicialmente la divergencia en los resultados de las diferentes encuestas generó incertidumbres (Semana 2016, 24 de agosto), al final de la campaña la mayoría de los sondeos daba una ventaja cómoda al Sí (Semana 2016, 28 de septiembre). El 2 de octubre, sin embargo, el No obtuvo 53 mil votos más que el Sí (menos de medio punto porcentual). ${ }^{5} \mathrm{Ni}$ siquiera la euforia que parecía atravesar el país pocos días antes luego de la fastuosa ceremonia de firma final del acuerdo por parte del presidente Santos y de Rodrigo Londoño, alias Timochenko, comandante supremo de las FARC, fue suficiente para que se lograra la refrendación del acuerdo (Caracol TV 2016, 26 de septiembre). Este resultado sorpresivo fue devastador para mucha gente, especialmente para el gobierno.

En las dos o tres semanas siguientes al plebiscito se dieron masivas movilizaciones ciudadanas en apoyo al proceso y exigiendo a los actores políticos llegar pronto a un nuevo acuerdo (El Espectador 2016, 6 de octubre). En respuesta, el gobierno y las FARC emitieron un comunicado corroborando su voluntad de alcanzar la paz mediante un nuevo acuerdo (Gobierno Nacional \& FARC-EP 2016i).

Durante ese tiempo, además, el gobierno adelantó conversaciones con diferentes voceros del No para recabar sus numerosas exigencias de modificación al acuerdo. Mientras que Uribe buscaba abrir una negociación tripartita con el gobierno y las FARC, iniciativa que fue rechazada por el primero (Semana 2016, 19 de octubre), en las reuniones con los voceros del No se recogieron cerca de 500 propuestas agrupadas alrededor de más de 50 ejes temáticos con los cuales el gobierno inició una ronda final de conversaciones con la guerrilla en La Habana.

Luego de varios días de tensas negociaciones (El Tiempo 2016, 16 de noviembre), el 12 de noviembre, el gobierno y las FARC informan que han alcanzado un nuevo acuerdo (CNNE 2016, 12 de noviembre) que se firmaría el 24 de noviembre en el Teatro Colón de Bogotá, en una ceremonia bastante más lánguida (El Colombiano 2016, 24 de noviembre). El nuevo texto recogía la gran mayoría de

Ver los resultados del plebiscito del 2 de octubre en la página de la Registraduría Nacional del Estado Civil (http://plebiscito.registraduria.gov.co/99PL/DPLZZZZZZZZZZZZZZZZZ_L1.htm). 
las modificaciones sugeridas por los voceros del No, con la notable excepción de la propuesta de limitar la elegibilidad de los miembros desmovilizados para cargos de elección popular, punto sobre el cual las FARC no transigieron (El Tiempo 2016, 16 de noviembre). ${ }^{6}$

Pese al rechazo y desconocimiento de algunos opositores, especialmente Uribe, al nuevo acuerdo y a su exigencia de un nuevo plebiscito (El Colombiano 2016, 22 de noviembre), este no fue sometido de nuevo a la votación popular y fue refrendado de forma expedita por el Congreso el 30 de noviembre (El Tiempo 2016, 1 de diciembre), lo cual determinó que el día D, base del cronograma de desmovilización y desarme de las FARC, así como de otros elementos de la implementación del acuerdo, quedó fijado para el 1 de diciembre (Gobierno Nacional \& FARC-EP 2016k). Aunque una nueva refrendación popular hubiera sido altamente arriesgada e inconveniente para los propósitos de la paz, el mecanismo elegido por el gobierno para este nuevo acuerdo, dado además el enorme desprestigio del Congreso, le dejó serios vicios de ilegitimidad que sus detractores aún denuncian.

Este año de vértigo cerró con la aprobación en la Corte Constitucional del procedimiento legislativo especial, conocido comofast track (CorteConstitucional C-699/16), la aprobación de la ley de amnistía por parte del Congreso (El Tiempo 2016, 28 de diciembre), la ceremonia de recepción del premio Nobel de Paz por parte del presidente Santos en Oslo (Nobelprize.org 2016) y la cifra más baja de homicidios en el país en los últimos 42 años (Ministerio de Defensa 2016; El País 2016, 31 de diciembre).

\section{OPINIÓN PÚBLICA: MALESTAR Y POLARIZACIÓN}

El año 2016 reafirmó una crisis de legitimidad de las instituciones democráticas que se venía mostrando desde un par de años atrás (García-Sánchez et al. 2015), que va de la mano de los bajos niveles de aprobación del gobierno del presidente Juan Manuel Santos y de una creciente fractura entre las élites políticas, que se materializa en la polarización alrededor de la figura del expresidente y hoy senador Álvaro Uribe (Botero 2014).

A pesar de los innegables logros en materia de desescalamiento del conflicto armado y de los avances del proceso de paz con las FARC, el presidente Santos ha debido afrontar niveles muy altos de desaprobación, especialmente cuando se comparan con la popularidad de la que gozó Uribe durante sus ocho años de gobierno; el Gráfico 1 muestra este contraste, que se pronuncia especialmente a partir de 2013.

El gobierno publicó un cuadro que resume las modificaciones introducidas al acuerdo, que puede consultarse en http://www.altocomisionadoparalapaz.gov.co/procesos-y-conversaciones/Documentos\%20compartidos/21-11-2016-CUADRO-Propuestas-y-Ajustes-definitivo.pdf. Para un análisis de estos cambios, ver El Tiempo (2016, 12 de noviembre) y Gobierno Nacional (2016). 
Gráfico 1. Aprobación de la gestión del presidente, 2004-2016

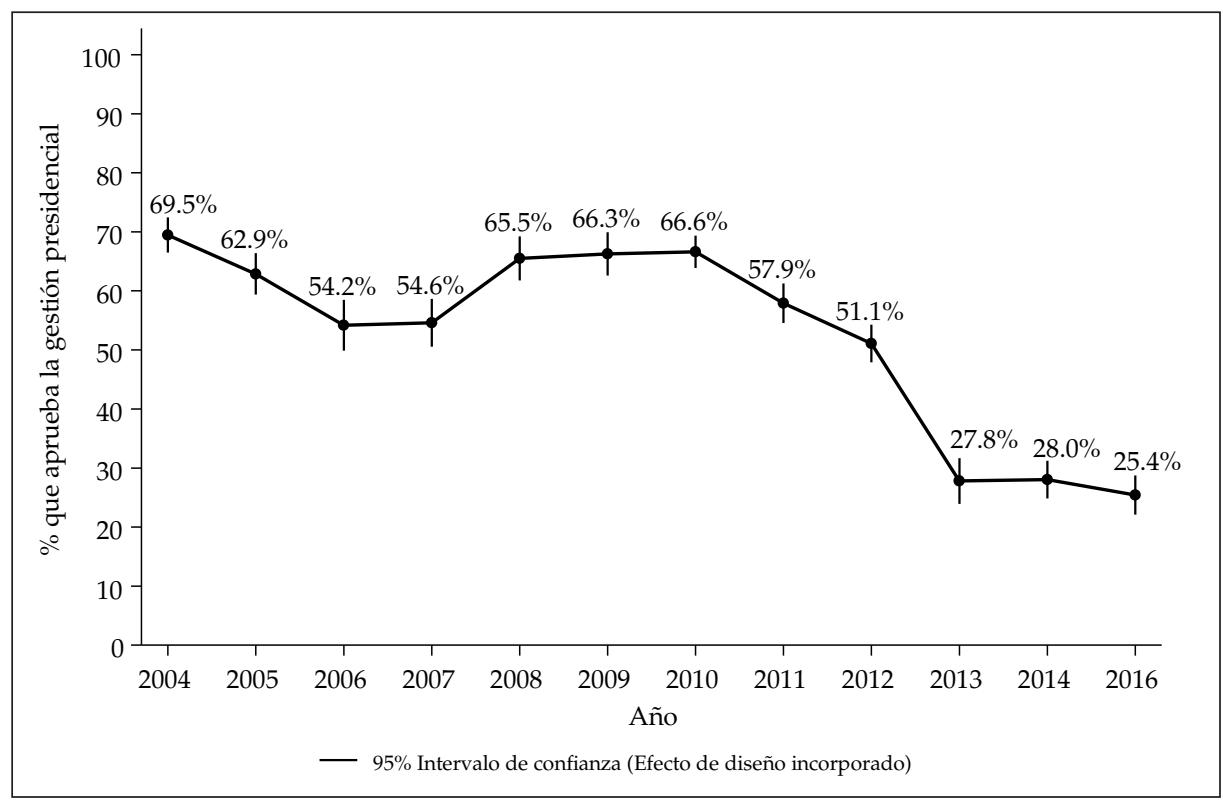

Fuente: Barómetro de las Américas-LAPOP.

Ni el desempeño económico ni mucho menos los indicadores del conflicto pueden explicar estos resultados. De hecho, los logros en seguridad de la administración Uribe, especialmente en su lucha contra las guerrillas, y los avances del proceso de negociación del gobierno Santos con las FARC contribuyeron a que la guerra dejara de ser la preocupación principal de los colombianos. El Gráfico 2 muestra que, mientras en 2008 cerca de dos de cada tres ciudadanos consideraba que la seguridad y el conflicto eran el principal problema del país, este porcentaje se redujo a una tercera parte en 2016. Las preocupaciones hoy son otras, incluyendo la pobreza y la corrupción, lo cual ha restado, paradójicamente, impacto a los logros de la paz con las FARC. 
Gráfico 2. Conflicto armado como el principal problema del país, 2004-2016

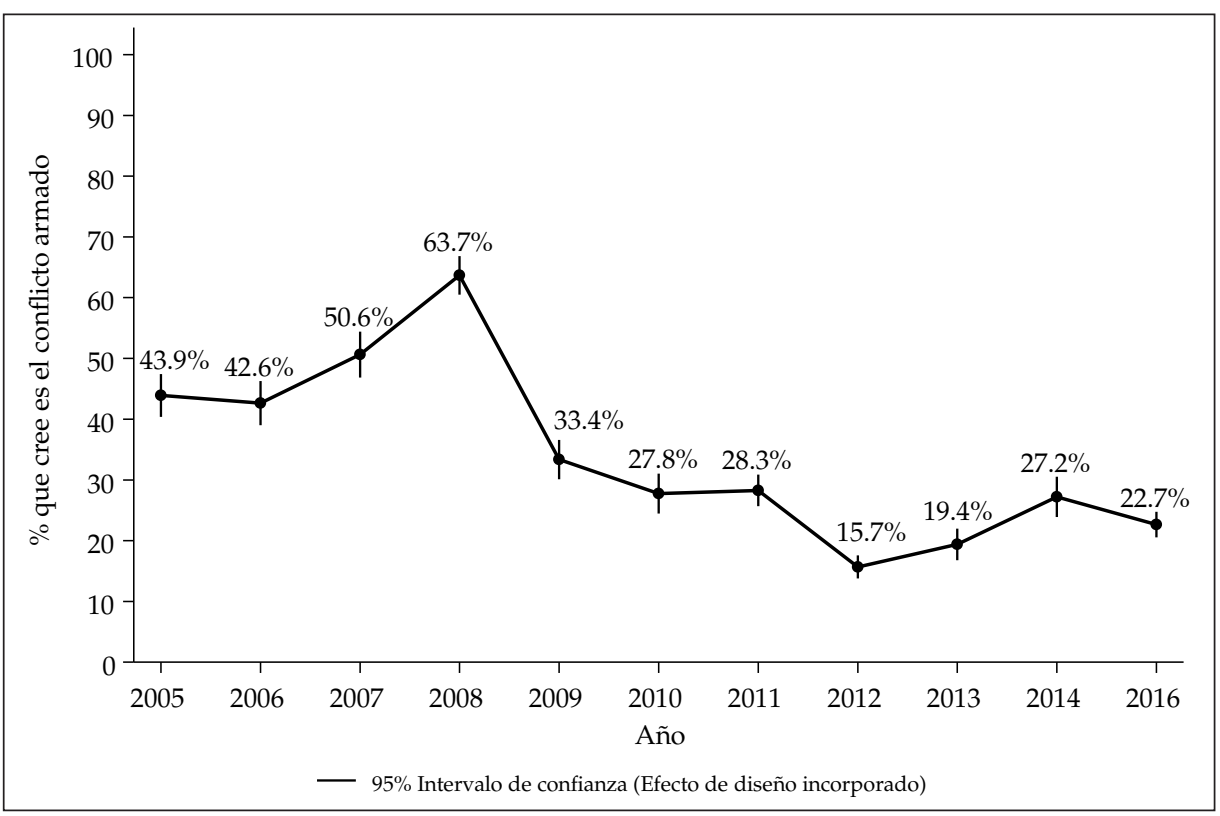

Fuente: Barómetro de las Américas-LAPOP.

Esta subvaloración de los pasos dados hacia el fin del conflicto, junto con la falta de carisma de Santos en su manera de comunicar estos pasos, explica su impopularidad y el clima de pesimismo que ha rodeado su gobierno, que se manifiesta en el hecho de que, de forma permanente durante los últimos años, la mayoría de las personas tiendan a ser de la opinión de que las cosas están empeorando (Gráfico 3). 
Gráfico 3. Percepción de que las cosas mejoran o empeoran en el país, 2014-2016

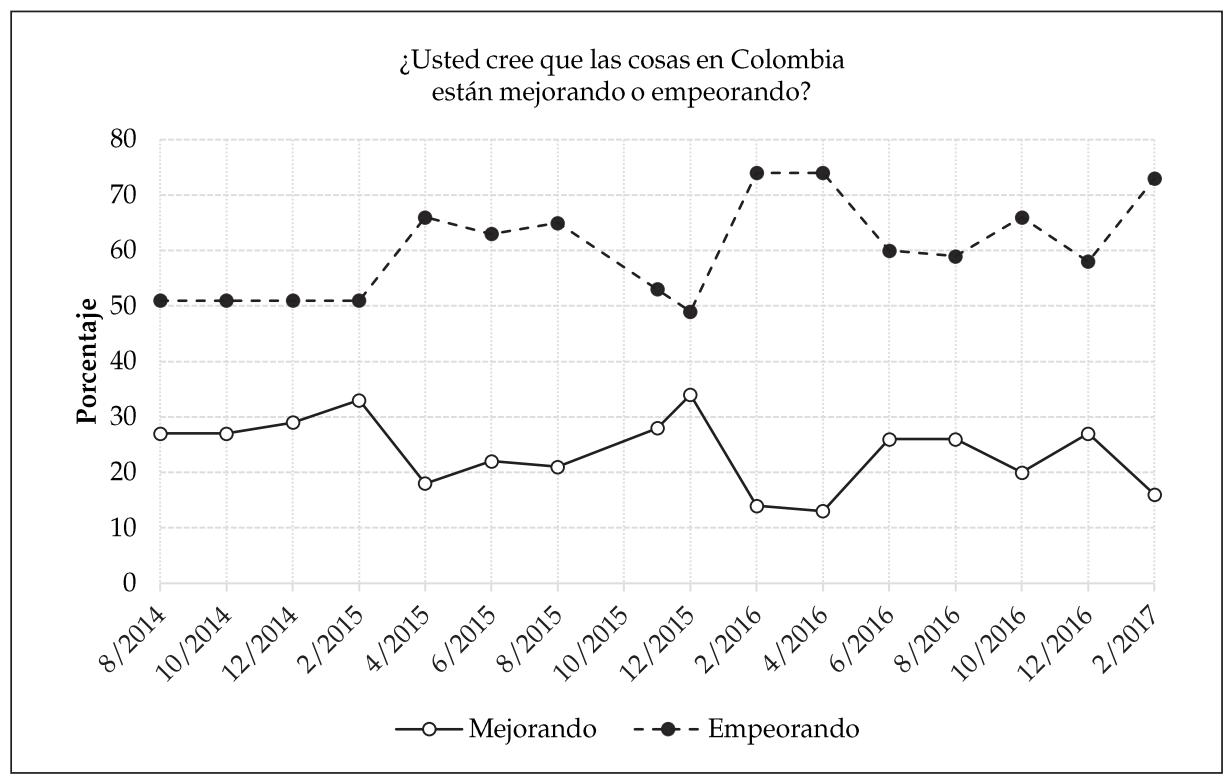

Fuente: elaboración propia sobre la base de Gallup (2017).

Esta baja apreciación de la figura y el desempeño de Santos se ha venido acompañando recientemente de cambios negativos no solo en los niveles de confianza ciudadana en las principales instituciones políticas del país, sino también, y de forma más preocupante, en las actitudes de apreciación del desempeño de la democracia y de apego al sistema democrático mismo.

En efecto, el descenso en la confianza que expresan los ciudadanos hacia el jefe del Ejecutivo ha arrastrado hacia abajo otras instituciones que, si bien no gozaban en el gobierno anterior del prestigio de la presidencia, han caído aun más en los últimos dos o tres años. El Gráfico 4 muestra esta tendencia conjunta en la confianza en el presidente, el Congreso, los partidos y el sistema de justicia. 
Gráfico 4. Confianza en el Congreso, los partidos políticos, el presidente y el sistema de justicia, 2004-2016

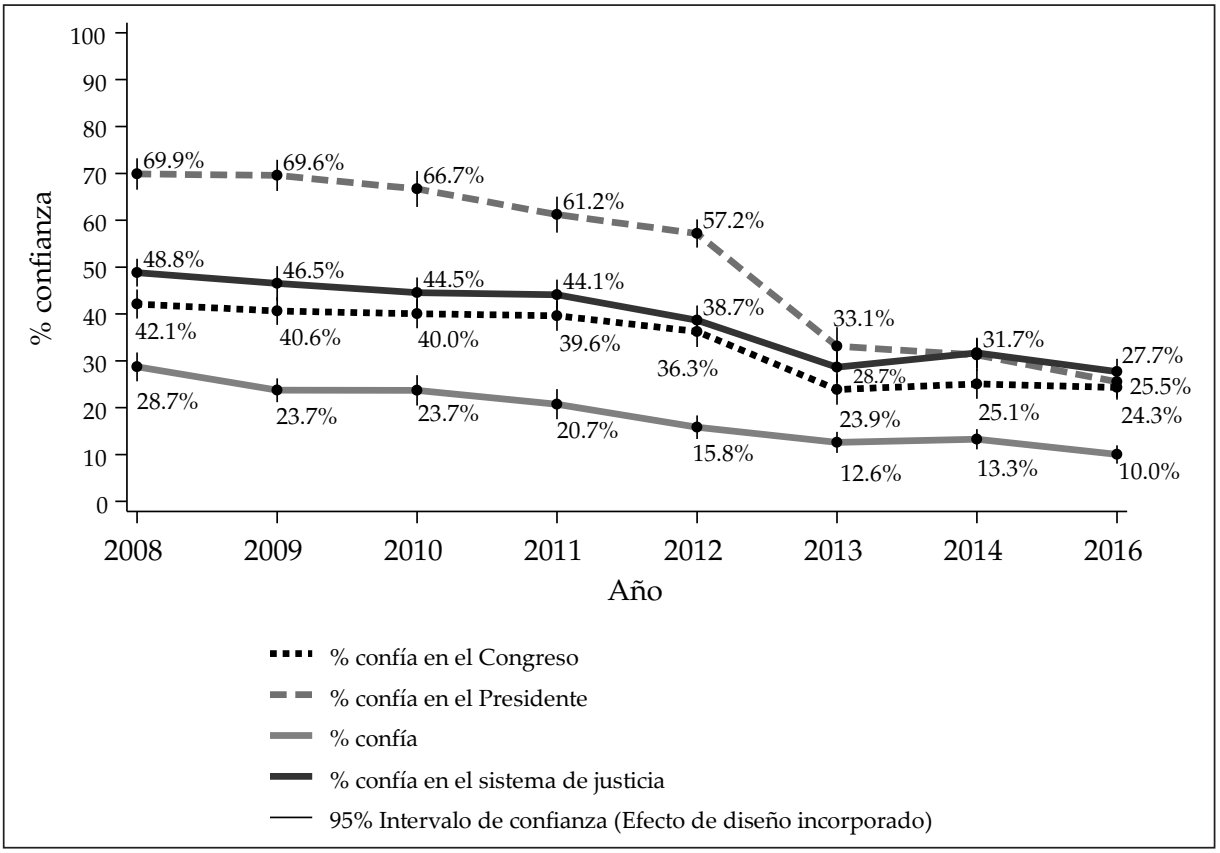

Fuente: Barómetro de las Américas-LAPOP.

Ahora bien, estas evaluaciones que, de alguna manera, tienden a responder más a la coyuntura, tienen un reflejo en actitudes que, en principio, deberían ser más estructurales. El Gráfico 5 muestra que, a partir de 2013, se dio una abrupta caída en la satisfacción ciudadana con el desempeño de la democracia, y que dicha caída no fue momentánea sino que la insatisfacción se mantuvo en los años subsiguientes.

Más preocupante aun, el porcentaje de personas que expresan afección a la democracia como la mejor forma de gobierno descendió en 2016 en más de quince puntos porcentuales con respecto a la medición anterior en 2014, como se ve en el Gráfico 6. 
Gráfico 5. Satisfacción con la democracia, 2004-2016

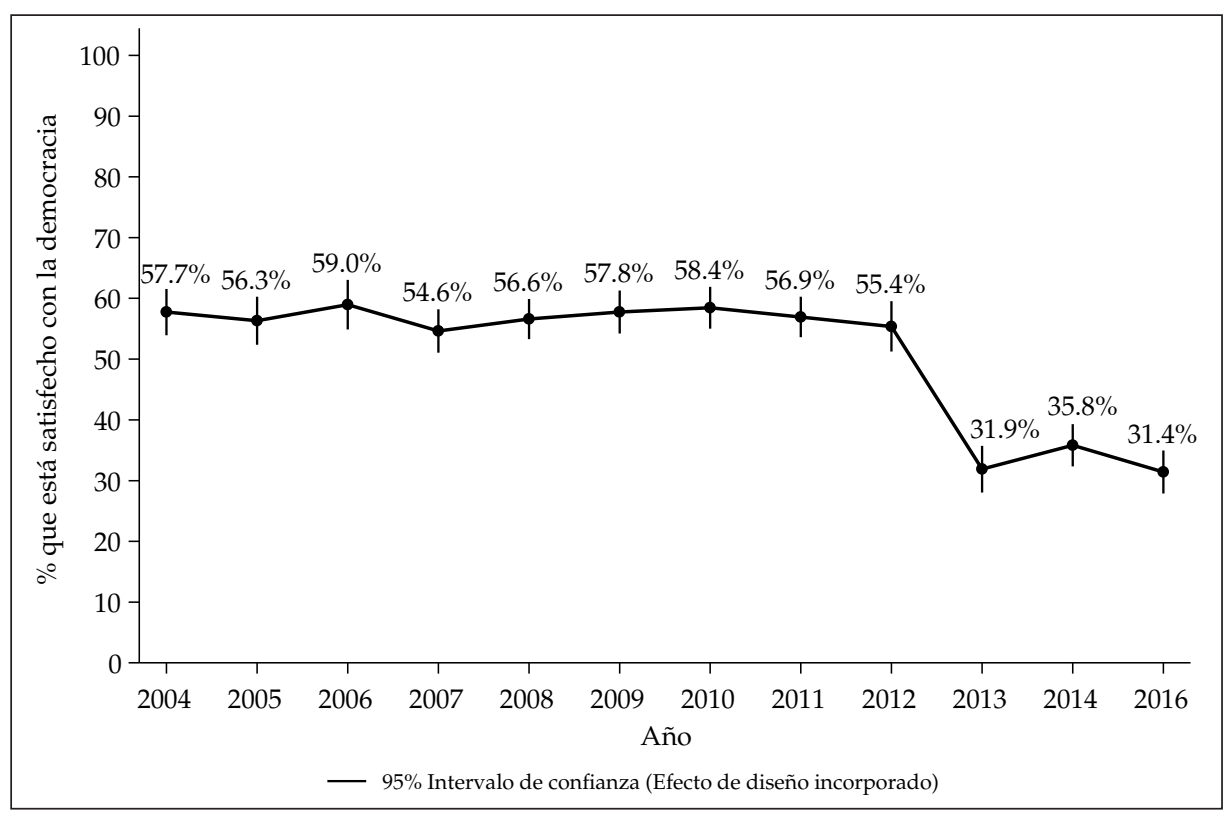

Fuente: Barómetro de las Américas-LAPOP.

Gráfico 6. Apoyo a la democracia como la mejor forma de gobierno, 2004-2016

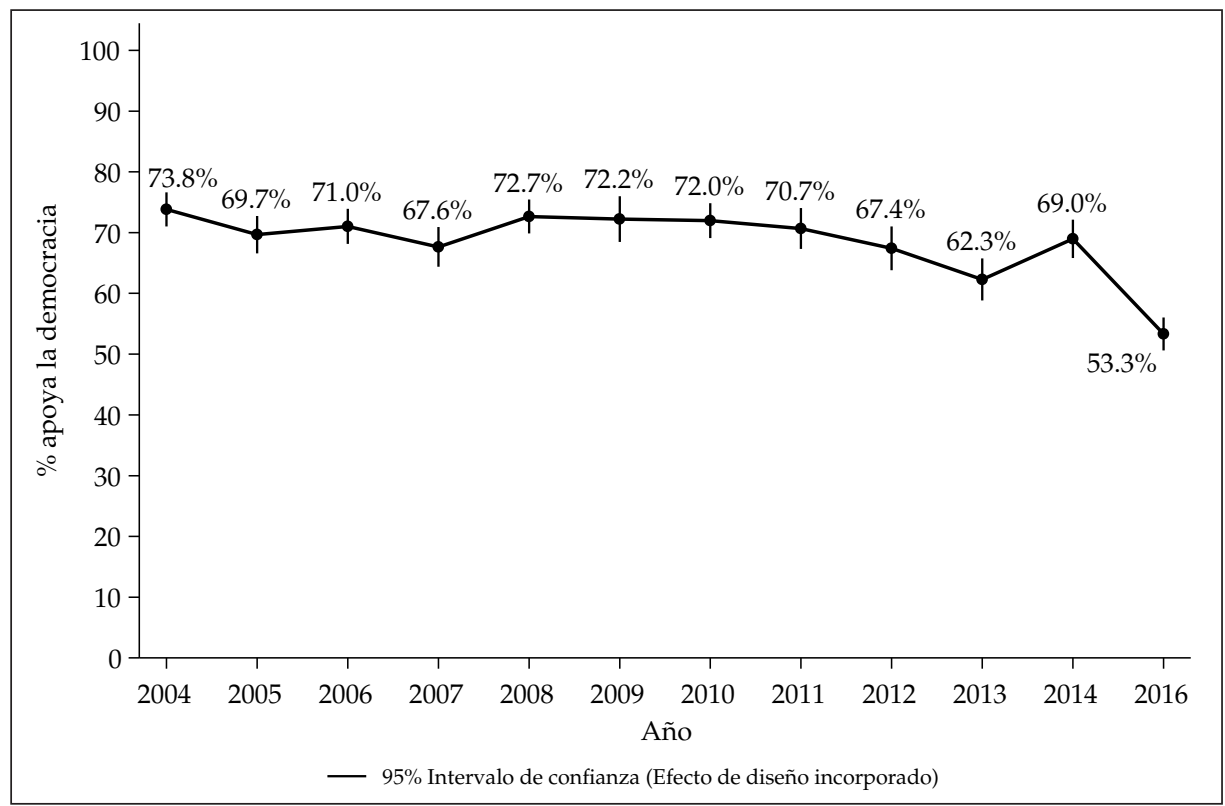

Fuente: Barómetro de las Américas-LAPOP. 
Los resultados de la encuesta de Barómetro de las Américas-LAPOP que aparecen en los gráficos anteriores dibujan un panorama de malestar en la ciudadanía en relación con el mundo político, y de crisis de las instituciones y de la democracia en el país. Este clima de la opinión pública podría convertirse en caldo de cultivo para que corrientes con poco apego a los principios de la democracia liberal intenten imponer propuestas populistas, de izquierda o de derecha.

Alrededor de esta situación, Matanock y García-Sánchez (2017) han sugerido que quizás el fenómeno que subyace no solo al resultado del plebiscito del 2 de octubre de 2016 sino también al malestar ciudadano descrito arriba, es el de una división en las élites que se expresa en una creciente polarización de estas y de la ciudadanía en general alrededor de la figura del expresidente y hoy senador Álvaro Uribe. ${ }^{7}$

La manifestación más obvia de esta división es quizás el contraste en la preferencia por una salida negociada al conflicto con la guerrilla. El Gráfico 7 muestra que durante la mayor parte del tiempo, durante los últimos diez años, el porcentaje de quienes se consideran seguidores de Uribe y que manifiestan tal preferencia es significativamente menor al de quienes no se dicen uribistas. De hecho, esta brecha se ha ensanchado en los últimos dos años.

Gráfico 7. Apoyo a una salida negociada al conflicto con la guerrilla (uribistas vs. no uribistas), 2006-2016

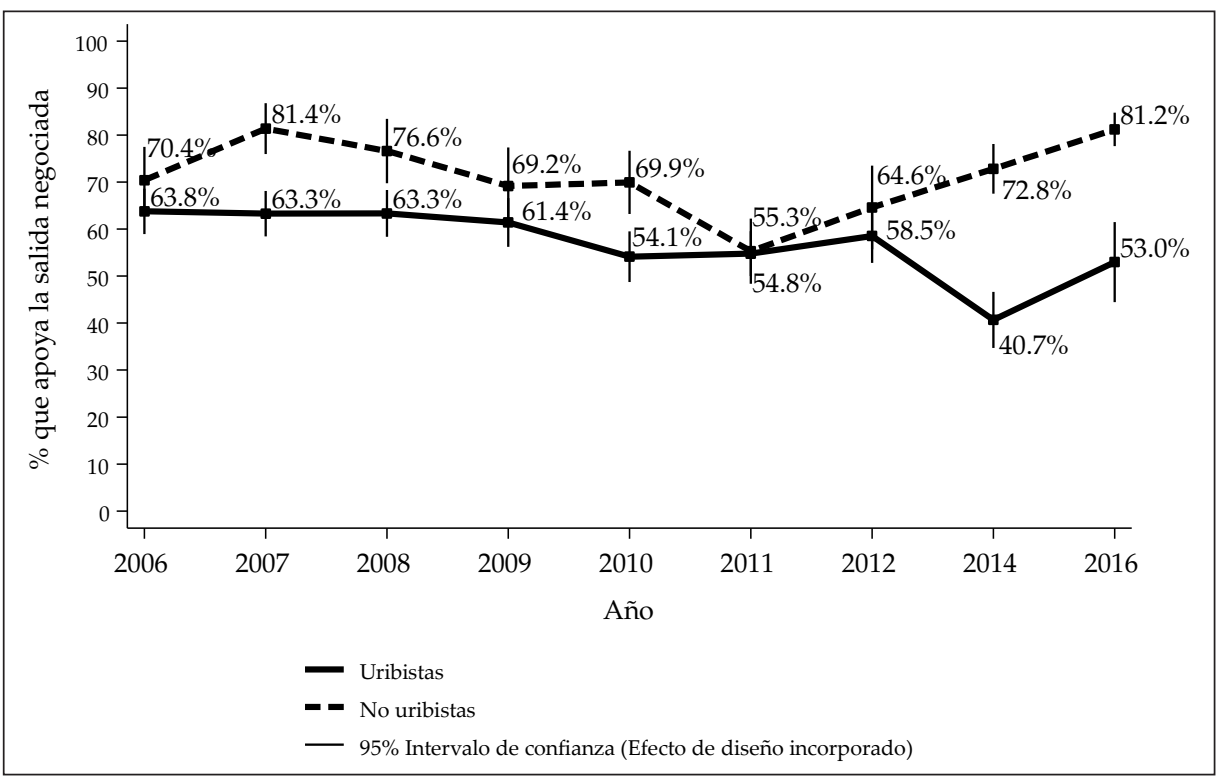

Fuente: Barómetro de las Américas-LAPOP.

Nasi \& Rettberg (2017) hablan incluso de una "sociedad dividida" no solo alrededor de asuntos directamente relacionados con el proceso de paz o la polarización uribismo vs. anti-uribismo sino también de otros temas que incluyen la economía, la corrupción y los derechos de las minorías sexuales, entre otros. 
Pero esta polarización no solamente se expresa alrededor del tratamiento que se debe dar al conflicto sino que se ha trasladado hacia actitudes más generales y abstractas en relación con las instituciones y el sistema político. Por ejemplo, durante el anterior gobierno los no uribistas manifestaban un respeto menor por las instituciones políticas que los uribistas, situación que se invierte a partir de 2012.

Más sorprendente aun, la apreciación que hacen los ciudadanos del desempeño del sistema democrático también parece marcada por la división entre quienes se sienten cercanos a los postulados del expresidente Uribe y quienes no. Si bien, como se observa en el Gráfico 8, la caída en la satisfacción con la democracia es generalizada en los últimos años, las actitudes relativas entre estos dos bandos se invierten en 2012, y en 2016 el porcentaje de uribistas satisfechos con el funcionamiento de la democracia colombiana es más de catorce puntos más bajo que el de los no uribistas.

Gráfico 8. Satisfacción con la democracia (uribistas vs. no uribistas), 2004-2016

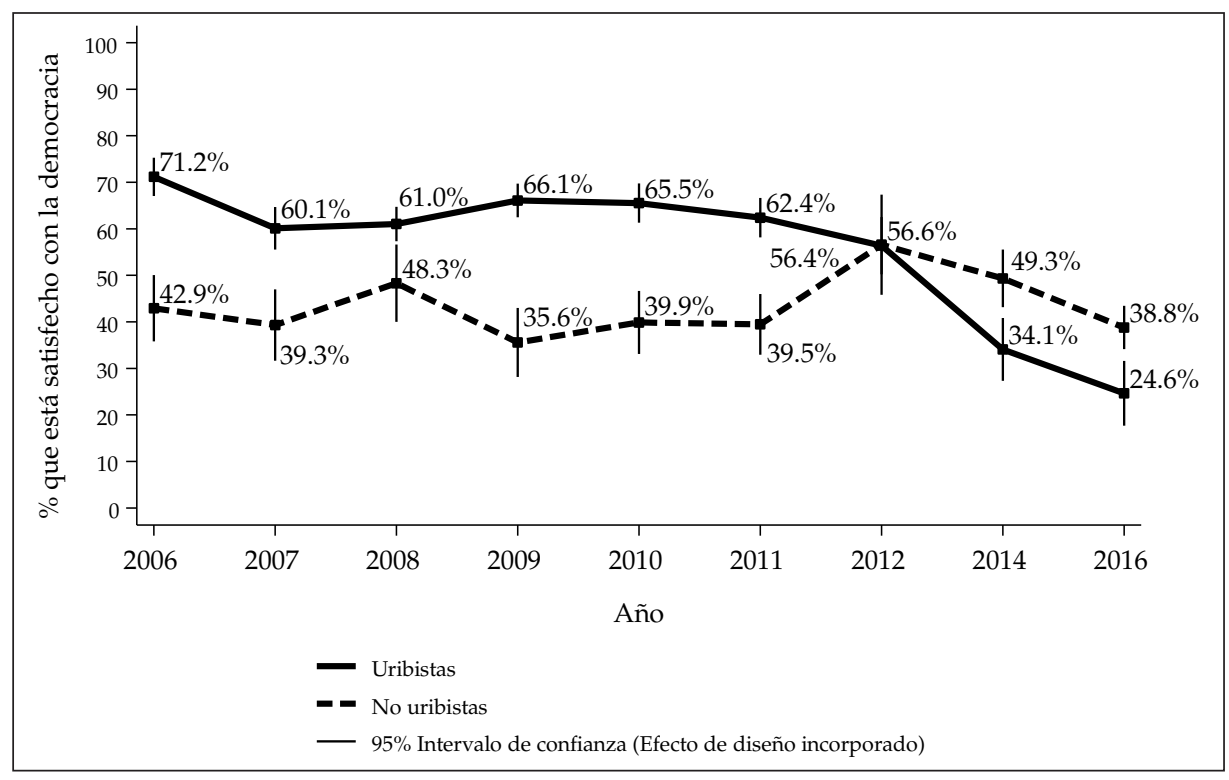

Fuente: Barómetro de las Américas-LAPOP.

En síntesis, en 2016 se consolida un clima de opinión cada vez más escéptico no solo frente al desempeño del gobierno y de las instituciones sino también frente a la democracia misma, pero la evolución de las actitudes ciudadanas está claramente marcada por la polarización reinante en el país alrededor de la figura y las posturas públicas del principal opositor al gobierno actual, el expresidente y hoy senador Álvaro Uribe. Esta polarización tuvo un punto de quiebre alrededor de 2012, cuando se terminó de definir el distanciamiento 
de Uribe hacia su exministro de defensa, el presidente Santos, alrededor de la decisión de este de iniciar conversaciones con el grupo guerrillero de las FARC, y que ha permeado actitudes frente al sistema político que van más allá de dichas conversaciones, como se evidencia arriba. La polarización descrita es un factor coadyuvante del anticlímax que caracterizó al país en 2016.

\section{ECONOMÍA: DESACELERACIÓN MANON TROPPO}

En un entorno de contracción como el que operó en América Latina en 2016, la desaceleración de la economía colombiana, si bien no constituye una buena noticia, resulta menos catastrófica. En efecto, el crecimiento del PIB pasó de 3,1\% en 2015 a solo $2 \%$ en 2016. Sin embargo, este resultado no se compara mal con el desempeño de otros países de América Latina donde la economía se contrajo - Argentina (-2\%), Ecuador (-2\%), Brasil (-3,6\%) o Venezuela (-9,7\%)- o donde el crecimiento fue aun menor - Chile $(1,6 \%)$. De hecho, entre países similares México tuvo un resultado parecido y solamente Perú registró un crecimiento superior $(3,9 \%)$.

Según el balance que hace la Asociación Nacional de Industriales (ANDI), el desempeño de la economía colombiana se ve todavía mejor si se considera la alta dependencia que tiene el país de los precios internacionales del petróleo tanto en materia de empleo como también en relación con la recaudación fiscal y la generación de divisas. Este desempeño permitió que las agencias calificadoras de riesgo (Moody's, Standard \& Poor y Fitch) mantuvieran en 2016 el grado de inversión para Colombia, calificación que compartió con un grupo de pocos países incluyendo Chile, México, Perú, Uruguay y Panamá (ANDI 2017).

La tasa de inflación no logró cumplir las metas del Banco de la República. Sin embargo, aunque al final del primer semestre del año mostraba una progresión acelerada —debido en parte al prolongado paro de conductores de transporte terrestre de carga en junio-, el país cerró 2016 con una tasa de inflación de $5,75 \%$, menor que la de 2015 (6,77\%). Por su parte, la tasa de desempleo se mantuvo en un dígito, aunque subió 3 décimas porcentuales, de 8,9\% en 2015 a 9,2\% en 2016. La Tabla 3 muestra los principales indicadores económicos del país durante los últimos tres años. 
Tabla 3. Principales indicadores económicos en Colombia, 2014-2016

\begin{tabular}{lccc}
\hline & 2014 & 2015 & 2016 \\
\hline PIB per capita (US\$ de 2005) & 4.661 & 4,858 & 4,788 \\
Crecimiento PIB (\% anual) & $4,4 \%$ & $3,1 \%$ & $2 \%$ \\
Inflación (\% anual) & $3,66 \%$ & $6,77 \%$ & $5,75 \%$ \\
Desempleo total (\% anual) & $9,1 \%$ & $8,9 \%$ & $9,2 \%$ \\
Déficit(\% PIB) & $2,4 \%$ & $3,0 \%$ & $4,0 \%$ \\
Precio del dólar (TRM OL\$/1US\$)) & $\$ 2.392,46$ & $\$ 3.149,47$ & $\$ 3.000,71$ \\
\hline
\end{tabular}

Fuente: Banco de la República (2017).

Como ya se mencionó, la economía colombiana es particularmente vulnerable a factores internacionales como la volatilidad de los precios de hidrocarburos. A esto se sumó la crisis energética ocasionada por el fenómeno de El Niño y que llevó al país al borde de un racionamiento eléctrico a principios del año. El gobierno, en su momento, aceptó su responsabilidad en la tardía reacción frente a esta situación al aceptar la renuncia del ministro de Minas y Energía, Tomás González (ver más adelante).

A estas circunstancias se sumó en junio un paro masivo y prolongado del gremio de los conductores de transporte terrestre de carga. El movimiento se inició el 5 de junio, liderado por la Asociación Colombiana de Camioneros (ACC), y buscaba mejores condiciones laborales para sus agremiados, aumento en los precios de los fletes, mayor seguridad en las vías, reducción en los costos de los peajes y en los precios del combustible (que no responden necesariamente a los precios internacionales del petróleo), entre otras demandas (Caracol 2016, 4 de junio). Se estima que más de 260.000 camiones pararon, dejando en evidencia la vulnerabilidad de la red vial del país (Colombia Informa 2016, 26 de junio). Al cabo de 46 días se llegó a un acuerdo después de una ardua negociación entre la ACC y el gobierno nacional (El Tiempo 2016, 22 de julio). El paro dejó serias consecuencias para la economía en términos de desabastecimiento, inflación y menor crecimiento.

A lo largo del año, el gobierno fue retrasando la presentación del esperado proyecto de reforma tributaria estructural. La coyuntura de la firma del acuerdo con las FARC y posteriormente del plebiscito para su refrendación ocasionaron este retraso ya que, naturalmente, un proyecto de esta naturaleza implicaba una inversión importante de capital político por parte de un gobierno al que de ninguna manera le sobraba. Por otra parte, las exigencias fiscales del posconflicto no permitían aplazar más dicha reforma que lograra el ingreso al fisco de recursos indispensables para la implementación de los diferentes componentes del acuerdo. El proyecto finalmente se presentó al Congreso apenas en octubre de 2016, acortando considerablemente el tiempo de discusión, y fue aprobado con la inclusión de medidas impopulares como la ampliación de la base gravable de 
personas naturales mediante un monotributo para pequeños establecimientos $\mathrm{y}$, sobre todo, como el aumento de impuesto al valor agregado (IVA) del $16 \%$ al 19\% (CEPAL 2017).

\section{VII.COMPOSICIÓN DEL GOBIERNO}

En abril de 2016, el presidente Santos realizó uno de los cambios ministeriales más profundos desde que asumió por primera vez en 2010, al reemplazar a los titulares de siete de los dieciséis ministerios del gabinete. Según el presidente, el propósito de esta renovación respondía a la necesidad de contar con un gabinete para la paz y el posconflicto (El Tiempo 2016, 23 de abril; Radio Santa Fe 2016, 25 de abril). Otros lo interpretaron en su momento como la inclusión de ministros con un perfil más político que técnico, con pasado en cargos de elección popular y con arraigo en las regiones, con el fin de liderar la campaña por el plebiscito que, se anticipaba, tendría lugar el segundo semestre del año (La Silla Vacía 2016, 04/26). Sin tocar cuatro de las principales carteras (Interior, Relaciones Exteriores, Hacienda y Defensa), los cambios se produjeron en los ministerios de Justicia; Trabajo; Minas y Energía; Comercio, Industria y Turismo; Ambiente y Desarrollo Sostenible; Vivienda, Ciudad y Territorio; y Transporte.

A principios de noviembre se produjo el último cambio ministerial del gobierno en 2016, esta vez forzado por la presión de la coyuntura. Desde agosto, la ministra de Educación Gina Parody se había visto envuelta en una controversia con grupos cristianos y católicos conservadores a raíz de la promoción desde el ministerio de una cartilla de educación sexual escolar llamada "Ambientes escolares libres de discriminación". La filtración del contenido de las cartillas originó una movilización sin precedentes de estos sectores que alegaban que dichos manuales de convivencia escolar promovían una "ideología de género" que atentaba contra los valores tradicionales de la familia (El Tiempo 2016, 10 de agosto). La movilización, con tintes claramente homofóbicos y dirigida específicamente en contra de la ministra —de orientación abiertamente homosexual一, afectó irremediablemente la relación que el gobierno buscaba consolidar con las iglesias cristianas con miras a la refrendación popular del acuerdo de paz con las FARC. El presidente resistió en su momento las presiones que pedían la cabeza de Parody, a quien encomendó labores de coordinación de la campaña del plebiscito. Dos días después de la derrota en las urnas del 2 de octubre, en la cual, como se dijo anteriormente, tuvo un importante papel la movilización de las congregaciones evangélicas en contra de la refrendación, Gina Parody finalmente renunció al ministerio de Educación (La Silla Vacía 2016, 4 de octubre; Semana 2016, 4 de octubre), vacante que el gobierno tardó casi un mes en llenar.

Al final del año, el gabinete contaba con seis mujeres (37,5\%), una más de las que terminaron el año anterior. Como en 2015, la mayoría de los titulares de las carteras hacían directa o indirectamente parte de los partidos de la coalición de gobierno (Partido Liberal, Partido de la U y Cambio Radical), con algunas 
excepciones del Partido Conservador (vg. el ministro de Hacienda, Mauricio Cárdenas) y con la llegada de Clara López, excandidata presidencial por el Polo Democrático, al ministerio de Trabajo. En la Tabla 4 se hace una relación de las personas que ocuparon los diferentes ministerios durante el segundo período del presidente Santos (2014-2016). ${ }^{8}$

Tabla 4. Gabinete ministerial (2014-2016)

\begin{tabular}{|c|c|c|c|c|c|}
\hline Ministerio & Ministro/a & Región & Filiación partidista & Inicio & Fin \\
\hline Interior & $\begin{array}{l}\text { Juan Fernando } \\
\text { Cristo }\end{array}$ & $\begin{array}{l}\text { Norte de } \\
\text { Santander }\end{array}$ & Liberal & 2014 & - \\
\hline $\begin{array}{l}\text { Relaciones } \\
\text { Exteriores }\end{array}$ & $\begin{array}{l}\text { María Ángela } \\
\text { Holguín }\end{array}$ & Bogotá & $\begin{array}{l}\text { Independiente } \\
\text { (cercana al P. } \\
\text { Liberal) }\end{array}$ & 2010 & - \\
\hline $\begin{array}{l}\text { Hacienda y Crédito } \\
\text { Público }\end{array}$ & $\begin{array}{l}\text { Mauricio } \\
\text { Cárdenas }\end{array}$ & Bogotá & Conservador & 2012 & - \\
\hline \multirow[t]{2}{*}{$\begin{array}{l}\text { Justicia y del } \\
\text { Derecho }\end{array}$} & Yesid Reyes & Bogotá & Independiente & 2014 & 2016 \\
\hline & Jorge Londoño & Boyacá & Alianza Verde & 2016 & - \\
\hline \multirow[t]{2}{*}{ Defensa Nacional } & $\begin{array}{l}\text { Juan Carlos } \\
\text { Pinzón }\end{array}$ & Bogotá & $\mathrm{La} \mathrm{U}$ & 2011 & 2015 \\
\hline & $\begin{array}{l}\text { Luis Carlos } \\
\text { Villegas }\end{array}$ & Risaralda & Liberal & 2015 & - \\
\hline $\begin{array}{l}\text { Agricultura y } \\
\text { Desarrollo Rural }\end{array}$ & Aurelio Iragorri & Cauca & La U & 2014 & - \\
\hline $\begin{array}{l}\text { Salud y Protección } \\
\text { Social }\end{array}$ & Alejandro Gaviria & Antioquia & Independiente & 2012 & - \\
\hline \multirow[t]{2}{*}{ Trabajo } & $\begin{array}{l}\text { Luis Eduardo } \\
\text { Garzón }\end{array}$ & Bogotá & Alianza Verde & 2014 & 2016 \\
\hline & Clara López & Bogotá & Polo Democrático & 2016 & - \\
\hline \multirow[t]{3}{*}{ Minas y Energía } & Tomás González & Bogotá & Conservador & 2014 & 2016 \\
\hline & $\begin{array}{l}\text { María Lorena } \\
\text { Gutiérrez } \\
\text { (encargada) }\end{array}$ & Bogotá & Independiente & 2016 & 2016 \\
\hline & Germán Arce & $\begin{array}{l}\text { Valle del } \\
\text { Cauca }\end{array}$ & Conservador & 2016 & - \\
\hline \multirow[t]{2}{*}{$\begin{array}{l}\text { Comercio, Industria } \\
\text { y Turismo }\end{array}$} & $\begin{array}{l}\text { Cecilia Álvarez- } \\
\text { Correa }\end{array}$ & Magdalena & Independiente & 2014 & 2016 \\
\hline & $\begin{array}{l}\text { María Claudia } \\
\text { Lacouture }\end{array}$ & Magdalena & $\mathrm{La} \mathrm{U}$ & 2016 & - \\
\hline \multirow[t]{2}{*}{ Educación Nacional } & Gina Parody & Bogotá & $\begin{array}{l}\text { Independiente } \\
\text { (cercana a La U) }\end{array}$ & 2014 & 2016 \\
\hline & Yaneth Giha & Atlántico & $\mathrm{La} \mathrm{U}$ & 2016 & - \\
\hline
\end{tabular}

Parte de la información de los perfiles de los ministros fue tomada de la sección Quién es Quién del portal La Silla Vacía (http://lasillavacia.com/quienesquien). 


\begin{tabular}{|c|c|c|c|c|c|}
\hline Ministerio & Ministro/a & Región & Filiación partidista & Inicio & Fin \\
\hline \multirow{2}{*}{$\begin{array}{l}\text { Ambiente y } \\
\text { Desarrollo } \\
\text { Sostenible }\end{array}$} & Gabriel Vallejo & Caldas & $\mathrm{La} \mathrm{U}$ & 2014 & 2016 \\
\hline & $\begin{array}{l}\text { Luis Gilberto } \\
\text { Murillo }\end{array}$ & Chocó & Cambio Radical & 2016 & - \\
\hline \multirow[t]{2}{*}{$\begin{array}{l}\text { Vivienda, Ciudad y } \\
\text { Territorio }\end{array}$} & Luis Felipe Henao & Antioquai & Cambio Radical & 2014 & 2016 \\
\hline & Elsa Noguera & Atlántico & Cambio Radical & 2016 & - \\
\hline \multirow{2}{*}{$\begin{array}{l}\text { Tecnologías de } \\
\text { Información y las } \\
\text { Comunicaciones }\end{array}$} & Diego Molano & Boyacá & Liberal & 2010 & 2015 \\
\hline & David Luna & Bogotá & Liberal & 2015 & - \\
\hline Cultura & Mariana Garcés & $\begin{array}{l}\text { Valle del } \\
\text { Cauca }\end{array}$ & Conservador & 2010 & 一 \\
\hline \multirow[t]{2}{*}{ Transporte } & Natalia Abello & Atlántico & Liberal & 2014 & 2016 \\
\hline & $\begin{array}{l}\text { Jorge Eduardo } \\
\text { Rojas }\end{array}$ & Caldas & La U & 2016 & - \\
\hline
\end{tabular}

Fuente: elaboración propia.

\section{PRODUCCIÓN LEGISLATIVA}

Durante 2016 el Congreso aprobó 51 leyes y un Acto Legislativo (enmienda constitucional). De las leyes, 18 (35\%) fueron de homenajes, celebraciones, estampillas, etc., mientras que $11(22 \%)$ se relacionaron con diferentes aspectos de la política social, incluyendo la lucha contra la pobreza o de atención a la primera infancia, política pública en salud, laboral o vivienda, entre otros. En la Tabla 5 y la Tabla 6 del Anexo aparece el detalle de las leyes y actos legislativos, respectivamente, aprobados en el Congreso durante 2016.

Cuatro de las leyes (8\%) constituyen pilares del proceso de paz, incluyendo reformas a la ley que reglamenta las zonas de reubicación y concentración de guerrilleros desmovilizados (11 de abril), la aprobación de un acuerdo marco con la Organización de Naciones Unidas para desplegar fuerzas de mantenimiento de la paz (11 de julio); la ley que regula el mecanismo de refrendación popular del acuerdo (24 de agosto); y la ley de amnistía e indulto y tratamientos penales especiales para miembros desmovilizados de grupos al margen de la ley (30 de diciembre).

El Acto Legislativo 01 de 2016 (7 de julio) introduce una reforma constitucional directamente relacionada con la implementación del acuerdo y que contiene cuatro artículos que otorgan al gobierno temporalmente facultades excepcionales para agilizar dicha implementación y blindarlo con el fin de hacerlo sostenible en el tiempo. 
En primer lugar, se estableció un procedimiento legislativo especial que permite que el Congreso apruebe las leyes y enmiendas constitucionales presentadas por el gobierno para la implementación del acuerdo mediante un trámite expedito que en el país se ha conocido como fast track. Este mecanismo no solo acorta el tiempo de debate de los proyectos en el Congreso, sino que además le da al gobierno tanto el poder de agenda como el de veto sobre ellos. En efecto, los proyectos de reforma constitucional, mediante este procedimiento ya no tendrían que superar ocho debates en el Congreso sino cuatro, a saber: uno en la comisión legislativa y uno en la plenaria de cada una de las cámaras (Senado y Cámara de Representantes). Por su parte, el trámite de los proyectos de ley se acorta a tres debates: uno en las comisiones legislativas conjuntas de Senado y Cámara, además de un debate en la plenaria de cada cuerpo legislativo. Además, estos proyectos de ley y de reforma constitucional son de iniciativa exclusiva del Ejecutivo, deben votarse en bloque, y no admiten enmiendas que no estén aprobadas previamente por el gobierno.

En segundo lugar, el Acto Legislativo le otorgaba durante 180 días facultades extraordinarias al presidente para emitir decretos con fuerza de ley destinados implementar el desarrollo normativo del acuerdo de paz.

En tercer lugar, permitía que el gobierno incluyera dentro del plan plurianual de inversiones del Plan Nacional de Desarrollo componentes específicos destinados a atender a las poblaciones y los territorios más afectados por el conflicto y que se encuentran en un relativo estado de abandono por parte del Estado. Estas inversiones tienen como objetivo crear las condiciones para que el acuerdo sea sostenible en el tiempo y se reduzcan los riesgos de repetición de la guerra.

Finalmente, la enmienda constitucional preveía que el acuerdo que se habría de firmar con las FARC fuera considerado como un Acuerdo Especial en consonancia con los Convenios de Ginebra, lo que implicaría que el texto del acuerdo en su integridad entrara al llamado "bloque de constitucionalidad" y se convirtiera en referente normativo constitucional para la revisión de las leyes y normas que deberían implementar los diferentes puntos del acuerdo.

La entrada en vigor de toda la reforma constitucional se daría a partir de la refrendación popular del Acuerdo. Como ya se mencionó, el intento del plebiscito del 2 de octubre fracasó. Posteriormente, sin embargo, el gobierno, en una jugada polémica y en menoscabo de su legitimidad, logró que el Acuerdo fuera refrendado en el Congreso. La Corte Constitucional, mediante una sentencia de control abstracto de diciembre de 2016, avaló dicha refrendación que, a lo sumo, era "popular" solo indirectamente, y, en consecuencia, le dio vía libre a las normas incluidas en este Acto Legislativo, en particular al procedimiento legislativo expedito descrito (Corte Constitucional C-699, 2016). 


\section{CONSIDERACIONES FINALES}

El plebiscito de octubre de 2016 resultó un punto de quiebre no solamente para el gobierno sino para la sociedad en general. Esta coyuntura crítica representó el punto supremo de un pulso entre el presidente Santos y su esfuerzo de cuatro años durante los cuales adelantó con paciencia y determinación un proceso de negociación con la guerrilla más antigua del mundo, las Fuerzas Armadas Revolucionarias de Colombia (FARC), y el sector liderado por el expresidente Álvaro Uribe. Fuela culminación de un proceso de distanciamiento y polarización entre dos figuras que en la primera década del siglo habían sido aliadas, Uribe en la presidencia y Santos como parte de su gabinete ministerial. El pulso se definió a favor de los enemigos del acuerdo de paz por un estrechísimo margen.

El triunfo del No, impulsado por diversos sectores cuyo abanderado fue Uribe, representó costos enormes a la legitimidad del acuerdo de paz, a pesar de haber sido eventualmente refrendado en el Congreso. Estos costos se han traducido en mayores dificultades para el trámite legislativo de las normas que han de implementar los diferentes puntos del acuerdo, aun a pesar del procedimiento legislativo especial, conocido como fast track. Aunque hasta ahora ninguno de estos proyectos de reforma constitucional o de ley ha sido rechazado en el Congreso, el gobierno ha debido laboriosamente negociar varios de los detalles de dichos proyectos con unas bancadas de la coalición que se muestran cada vez más reticentes a seguir las directrices del presidente.

Esta situación de debilidad del gobierno y de relativa fragilidad del acuerdo de paz con las FARC se ve crecientemente agudizada por la entrada, en 2017, a un período preelectoral. De hecho, lejos de que la firma de la paz signifique el inicio de una nueva etapa para el país, las elecciones legislativas de marzo de 2018 y presidenciales de mayo del mismo año prometen convertirse nuevamente en una disputa alrededor del conflicto armado. El debate girará alrededor de un bando comprometido con el cumplimiento del acuerdo y otro empeñado en revertir varios de sus puntos.

A pesar de la firma del acuerdo que ha representado una reducción drástica en los niveles de violencia política y la desmovilización de cerca de 7000 miembros de las FARC, a pesar del premio Nobel de la Paz para Santos, del galardón de "país del año" de The Economist y del amplio reconocimiento internacional, 2016 no fue un año de euforia. En Colombia, fue el año del anticlímax.

\section{REFERENCIAS}

ANDI. 2017. “Colombia: balance 2016 y perspectivas 2017." Recuperado el 11 de abril de 2017 de http://www.andi.com.co/SitEco/Documents/ANDI-Balance\%202016-Perspectivas\%202017.pdf

Banco de la República. 2017. "Boletín de indicadores económicos." Recuperado el 10 de junio de 2017 de http:/ / www.banrep.gov.co/economia/pli/bie.pdf 
Botero, Felipe. 2014. "The Legislative and Executive Elections in Colombia, 2014." Electoral Studies 36(Diciembre): 225-229.

Caracol. 2016, 4 de junio. "Anuncian paro camionero a partir de las cero horas del lunes festivo." Recuperado el 4 de abril de 2017 de http:/ /caracol.com.co/radio/2016/06/04/ nacional/1465004902_611513.html

Caracol. 2016, 5 de junio. "Las FARC esperan que gane el Sí en el plebiscito." Recuperado el 30 de marzo de 2017 de http://caracol.com.co/radio/2016/06/22/politica/1466563227_216380.html

Caracol TV. 2016, 26 de setiembre. “'Les doy la bienvenida a la democracia': Santos y 'Timochenko' firman acuerdo final". Recuperado el 30 de marzo de 2017 de http:/ / noticias. caracoltv.com/acuerdo-final/minuto-minuto-gobierno-y-farc-firman-la-paz-en-cartagena

Centro Nacional de Memoria Histórica. 2017. “Estadísticas del conflicto armado en Colombia." Recuperado el 30 de marzo de 2017 de http:/ / www.centrodememoriahistorica. gov.co/micrositios/informeGeneral/estadisticas.html

CEPAL. 2017. "Balance preliminar de las economías de América Latina y el Caribe, 2016: Colombia." Recuperado el 4 de abril de 2017 de http:/ / repositorio.cepal.org/bitstream/ handle/11362/40825/17/1601260BP_Colombia_es.pdf

CNNE. 2016, 24 de agosto. "Gobierno de Colombia y FARC firman histórico acuerdo final de paz." Recuperado el 30 de marzo de 2017 de http:/ / cnnespanol.cnn.com/2016/08/24 / minuto-a-minuto-el-anuncio-del-fin-de-la-negociacion-de-paz-en-colombia/

CNNE. 2016, 25 de agosto. "Juan Manuel Santos ordena el cese al fuego definitivo con las FARC." Recuperado el 30 de marzo de 2017 de http://cnnespanol.cnn.com/video/ cnnee-brk-paz-santos-colombia-plebicito/

CNNE. 2016, 12 de noviembre. "Gobierno y FARC alcanzan nuevo acuerdo de paz con propuestas de partidarios del no." Recuperado el 30 de marzo de 2017 de http:/ / cnnespanol.cnn.com/2016/11/12/gobierno-y-farc-alcanzan-nuevo-acuerdo-de-paz-conpropuestas-de-partidarios-del-no/

Colombia Informa. 2016, 26 de junio. "El ABC del paro camionero." Recuperado el 4 de abril de 2017 de http:/ /www.colombiainforma.info/el-abc-del-paro-camionero/

Corte Constitucional C-699/2016. 2016. Recuperada el 4 de abril de 2017 de http://www. corteconstitucional.gov.co/relatoria/2016/c-699-16.htm

Dugas, John. 1993. La Constitución de 1991: ¿un pacto político viable? Bogotá: Departamento de Ciencia Política, Universidad de Los Andes.

El Colombiano. 2016, 18 de julio. "Corte Constitucional aprueba el plebiscito por la paz." Recuperado el 30 de marzo de 2017 de http://www.elcolombiano.com/colombia/ paz-y-derechos-humanos/plebiscito-por-la-paz-aprobado-por-la-corte-constitucional-KK4590396

El Colombiano. 2016, 6 de octubre. “'Estábamos buscando que la gente saliera a votar verraca': Juan C. Vélez." Recuperado el 30 de marzo de 2017 de http://www.elcolombiano. com/colombia/acuerdos-de-gobierno-y-farc/entrevista-a-juan-carlos-velez-sobre-laestrategia-de-la-campana-del-no-en-el-plebiscito-CE5116400

El Colombiano. 2016, 22 de noviembre. “Uribe rechaza nuevo acuerdo de paz entre el Gobierno y las FARC y pide un nuevo plebiscito." Recuperado el 30 de marzo de 2017 de http: / / internacional.elpais.com/internacional/2016/11/22/colombia/1479819217_374727. html

El Colombiano. 2016, 24 de noviembre. "Gobierno y FARC firmaron el nuevo acuerdo de paz." Recuperado el 30 de marzo de 2017 de http:/ / www.elcolombiano.com/colombia/acuerdos-de-gobierno-y-farc/vea-la-firma-del-nuevo-acuerdo-de-paz-entre-elgobierno-y-las-farc-AN5429376

El Espectador. 2016, 9 de junio. “Cámara de Representantes concluye aprobación de blindaje jurídico de Acuerdo de Paz." Recuperado el 30 de marzo de 2017 de http://www. elespectador.com/noticias/politica/camara-de-representantes-concluye-aprobacion-de-blindaj-articulo-636845 
El Espectador. 2016, 6 de octubre. "Con multitudinaria marcha, ciudadanos pidieron no dejar morir los acuerdos." Recuperado el 30 de marzo de 2017 de http: / / www.elespectador. com/noticias/paz/multitudinaria-marcha-ciudadanos-pidieron-no-dejar-mori-articulo-658833

El Heraldo. 2016, 9 de marzo. "Con unánime apoyo del uribismo, Senado aprueba zonas de ubicación de guerrilleros." Recuperado el 30 de marzo de 2017 de https: / www.elheraldo.co/politica/con-unanime-apoyo-del-uribismo-senado-aprueba-zonas-de-ubicacion-de-guerrilleros-247810

El País. 2016, 31 de diciembre. "Colombia cierra 2016 con la cifra más baja de homicidios en 42 años." Recuperado el 30 de marzo de 2017 de http:/ / internacional.elpais.com/internacional/2016/12/31/colombia/1483187941_964829.html?id_externo_rsoc=TW_CM

El Tiempo. 2016, 23 de abril. "Presidente Santos preparara nuevo gabinete para tiempos de paz." Recuperado el 30 de marzo de 2017 de http:/ / www.eltiempo.com/archivo/documento/CMS-16570946

El Tiempo. 2016, 22 de julio. "Este es el acuerdo que terminó con 46 días de paro camionero." Recuperado el 4 de abril de 2017 de http: / / www.eltiempo.com/archivo/documento / CMS-16651085

El Tiempo. 2016, 10 de agosto. "Así fue la marcha contra los supuestos cambios en los manuales de convivencia." Recuperado el 30 de marzo de 2017 de http:/ /www.eltiempo.com/colombia/otras-ciudades/protestas-contra-cartillas-de-ideologia-de-genero-en-colegios-42293

El Tiempo. 2016, 23 de setiembre. "Procurador Alejandro Ordónez presentó renuncia al Senado." Recuperado el 30 de marzo de 2017 de http://www.eltiempo.com/justicia/ cortes / renuncia-y-fallo-del-procurador-alejandro-ordonez-42754

El Tiempo. 2016, 25 de octubre. “Líderes 'azules' del 'No' volvieron a Palacio a reunión con Santos.” Recuperado el 30 de marzo de 2017 de http:/ / www.eltiempo.com/politica / proceso-de-paz/reunion-entre-promotores-del-no-y-el-presidente-santos-28190

El Tiempo. 2016, 12 de noviembre. "Cinco claves para entender el nuevo acuerdo de La Habana." Recuperado el 30 de marzo de 2017 de http://www.eltiempo.com/politica/ proceso-de-paz/los-cambios-que-trae-el-nuevo-acuerdo-de-paz-42548

El Tiempo. 2016, 16 de noviembre. "Los diez momentos de tensión que marcaron la renegociación del Acuerdo." Recuperado el 30 de marzo de 2017 de http:/ / www.eltiempo. com/politica / proceso-de-paz/como-se-construyo-el-nuevo-acuerdo-de-paz-57008

El Tiempo. 2016, 1 de diciembre. "La histórica votación a la refrendación del acuerdo en el Congreso." Recuperado el 30 de marzo de 2017 de http:/ /www.eltiempo.com/politica/proceso-de-paz/como-fue-la-votacion-en-congreso-para-refrendar-nuevo-acuerdo-de-paz-31402

El Tiempo. 2016, 28 de diciembre. "Congreso aprobó ley de amnistía a excombatientes de FARC y militares." Recuperado el 30 de marzo de 2017 de http://www.eltiempo. com/politica/proceso-de-paz/ley-de-amnistia-aprobada-en-el-congreso-50276

Gallup 2017. “Gallup Poll \#117, Colombia, febrero 2017”. Recuperado el 10 de abril de 2017 http:/ / www.eltiempo.com/contenido/politica/gobierno/ARCHIVO/ARCHIVO-16832164-0.pdf

García-Sánchez, Miguel, Juan Carlos Rodríguez-Raga, Mitchell A. Seligson \& Elizabeth J. Zeichmeister. 2015. Cultura Politica de la Democracia en Colombia, 2014. Dilemas de la democracia y desconfianza institucional en el marco del proceso de paz. Bogotá: USAID-Vanderbilt University.

Gobierno Nacional. 2016. "Notas sobre los cambios, ajustes y precisiones del nuevo acuerdo final para la terminación del conflicto y la construcción de la paz estable y duradera." Recuperado el 30 de marzo de 2017 de http:/ /equipopazgobierno.presidencia. gov.co/Documents/NOTAS-SOBRE-LOS-CAMBIOS-AJUSTES-PRECISIONES-NUEVO-ACUERDO-FINAL.pdf

Gobierno Nacional y FARC-EP. 2012. "Acuerdo General para la terminación del conflicto y la construcción de una paz estable y duradera." Recuperado el 30 de marzo de 2017 de 
https:/ / www.mesadeconversaciones.com.co/sites/default/ files / AcuerdoGeneralTerminacionConflicto.pdf

Gobierno Nacional y FARC-EP. 2016a. “Comunicado Conjunto \#65.” Recuperado el 30 de marzo de 2017 de http:/ / www.humanas.org.co/archivos/comunicadoconjunto65.pdf

Gobierno Nacional y FARC-EP. 2016b. “Comunicado Conjunto \#65." Recuperado el 30 de marzo de 2017 de http://www.humanas.org.co/archivos/comunicadoconjunto65. pdf

Gobierno Nacional y FARC-EP. 2016c. “Comunicado Conjunto \#69.” Recuperado el 30 de marzo de 2017 de http:/ /www.humanas.org.co/archivos/130516_Comunicado-Conjunto-69-12-de-mayo-de-2016.pdf

Gobierno Nacional y FARC-EP. 2016d. "Acuerdo sobre el cese al fuego y de hostilidades bilateral y definitivo y dejación de armas entre el Gobierno Nacional y las FARC-EP." Recuperado el 30 de marzo de 2017 de http: / / www.humanas.org.co/archivos/230616_ AcuerdoSobreCeseAlFuego.pdf

Gobierno Nacional y FARC-EP. 2016e. “Comunicado Conjunto \#80." Recuperado el 30 de marzo de 2017 de http://www.humanas.org.co/archivos/06-07-2016-comunicado-conjunto-80.pdf

Gobierno Nacional y FARC-EP. 2016f. “Comunicado Conjunto \#81." Recuperado el 30 de marzo de 2017 de http: / / equipopazgobierno.presidencia.gov.co/prensa/Paginas/comunicado-conjunto-revision-subcomision-genero-acuerdos-paz-habana.aspx

Gobierno Nacional y FARC-EP. 2016g. "Comunicado Conjunto \#83." Recuperado el 30 de marzo de 2017 de http: / / www.humanas.org.co/archivos/Comunicado_83.pdf

Gobierno Nacional y FARC-EP. 2016h. “Comunicado Conjunto \#88." Recuperado el 30 de marzo de 2017 de http: / / equipopazgobierno.presidencia.gov.co/prensa/Paginas / comunicado-conjunto-mecanismo-seleccion-magistrados-jurisdiccion-especial-paz.aspx

Gobierno Nacional y FARC-EP. 2016i. “Acuerdo Final 24.08.2016." Recuperado el 30 de marzo de 2017 de http:/ / www.humanas.org.co/archivos/24_08_2016acuerdofinalfinalfinal. pdf

Gobierno Nacional y FARC-EP. 2016j. “Comunicado Conjunto 02." Recuperado el 30 de marzo de 2017 de http://www.humanas.org.co/archivos/071016_COMUNICADO_CONJUNTO_02.pdf

Gobierno Nacional y FARC-EP. 2016k. “Comunicado Conjunto 08." Recuperado el 30 de marzo de 2017 de http://www.altocomisionadoparalapaz.gov.co/procesos-y-conversaciones / documentos-y-comunicados-conjuntos/Paginas / Comunicado-Conjunto-No-8-1-de-diciembre-de-2016.aspx

Gutiérrez, Francisco. 2011. “La Constitución de 1991 como pacto de paz: discutiendo las anomalías." Revista Estudios Socio-Jurídicos 13(1): 419-447

Huffington Post. 2013, 20 de abril. "Juan Manuel Santos: «Con las FARC, nada está acordado hasta que todo esté acordado»." Recuperado el 10 de junio de 2017 de http:/ /www. huffingtonpost.es/vladdo/entrevista-a-juan-manuel-_b_3115143.html

La Silla Vacía 2016, 26 de abril. “Un gabinete para el plebiscito.” Recuperado el 30 de marzo de 2017 de http:/ / lasillavacia.com/historia/un-gabinete-para-el-plebiscito-55584

La Silla Vacía, 4 de octubre. "Gina Parody, la primera sacrificada del movimiento religioso." Recuperado el 30 de marzo de 2017 de http://lasillavacia.com/historia/gina-parody-la-primera-sacrificada-del-movimiento-religioso-58198)

Matanock, Aila \& Miguel García-Sánchez. 2017. “The Colombian Paradox: Peace Process, Elite Divisions, and Popular Plebiscites." Daedalus (en prensa)

Ministerio de Defensa. 2016. "Mindefensa reportó la cifra más baja de homicidios de los últimos 42 años." Recuperado el 30 de marzo de 2017 de https:/ / www.mindefensa.gov. $\mathrm{co} / \mathrm{irj} / \mathrm{portal} /$ Mindefensa/contenido/noticiamdn?idXml=603299c5-75af-3410-b588 -f06086c2d9d2\&date $=28112016$

Nasi, Carlo y Angelika Rettberg. 2017. “Colombia's Farewell to Civil War: Reaching Closure in a Divided Society". En How Negotiations End, editado por William Zartman (próxi- 
ma publicación). Recuperado de https://papers.ssrn.com/sol3/Delivery.cfm/SSRN_ ID2945073_code1341307.pdf?abstractid=2816834\&mirid=1

Nobelprize.org. 2016. "The Nobel Peace Prize 2016: Juan Manuel Santos." Recuperado el 30 de marzo de 2016 de https://www.nobelprize.org/nobel_prizes/peace/laureates/2016/presentation-speech_sp.html

Oficina del Alto Comisionado para la Paz. 2016. "Acuerdo final para la terminación del conflicto y la construcción de una paz estable y duradera (24.11.2016)," Recuperado el 28 de marzo de 2017 de http:/ / www.altocomisionadoparalapaz.gov.co/mesadeconversaciones/PDF/24-1480106030.11-1480106030.2016nuevoacuerdofinal-1480106030.pdf

Pacifista. 2016. “En imágenes: así se vivió en Bogotá el anuncio del fin de las conversaciones de paz." Recuperado el 30 de marzo de 2017 de http:/ / pacifista.co/en-imagenes-asise-vivio-en-bogota-el-anuncio-del-fin-de-las-conversaciones-de-paz/

Presidencia de la República. 2016. "Gobierno y partidos acuerdan Pacto por la Paz." Recuperado el 30 de marzo de 2017 de http:/ / es.presidencia.gov.co/noticia/Gobierno-y-partidos-politicos-acuerdan-Pacto-por-la-Paz

Presidencia de la República. 2017. “Normativa”. Recuperado el 4 de abril de 2017 de http:// es.presidencia.gov.co/normativa/normativa/Forms/AllItems.aspx

Radio Santa Fe. 2016, 25 de abril. “'Revolcón' ministerial, Presidente Santos designó siete nuevos integrantes del gabinete." Recuperado el 30 de marzo de 2017 de http://www. radiosantafe.com/2016/04/25/revolcon-ministerial-presidente-santos-designo-siete-nuevos-integrantes-del-gabinete/

Santos Calderón, Enrique. 2014. Así empezó todo. El primer cara a cara secreto entre el gobierno y las FARC en La Habana. Bogotá: Intermedio.

Semana. 2012, 1 de setiembre. "Secretos de la negociación." Recuperado el 10 de junio de 2017 de http://www.semana.com/nacion/articulo/secretos-negociacion/263986-3

Semana. 2016, 24 de agosto. "Las encuestas que hay no son comparables." Recuperado el 30 de marzo de 2017 de http:/ /www.semana.com/nacion/multimedia/las-encuestas-quehay-no-son-comparables/489795

Semana. 2016, 28 de agosto. "Colombia despierta sin guerra con las FARC." Recuperado el 30 de marzo de 2017 de http:/ / www.semana.com/nacion/articulo/proceso-de-paz-cese-al-fuego-bilateral-y-definitivo-entre-gobierno-y-farc-empieza-este-lunes / 491631

Semana. 2016, 28 de setiembre. "Juan Carlos Rodríguez, director del Observatorio de la Democracia de la Universidad de los Andes, habla sobre las encuestas del \#plebiscitoporlapaz." Recuperado el 30 de marzo de 2017 de https:/ / m.facebook.com/story.php?story_fbid $=10155261826276679 \& i d=97041406678 \& \_r d r$

Semana. 2016, 4 de octubre, "Gina Parody renuncia como ministra de educación." Recuperado el 30 de marzo de 2017 de http://www.semana.com/educacion/articulo/renuncia-de-gina-parody/497734

Semana. 2017, 24 de febrero, "El día que iniciaron las conversaciones secretas con las FARC hace cinco años," Recuperado el 10 de junio de 2017 de http://www.semana.com/ nacion/articulo/como-iniciaron-las-conversaciones-entre-las-farc-y-el-gobierno-colombiano-asi-empezo-todo-enrique-santos-calderon/516584

The Economist. 2016, 24 de diciembre. "Our Country of the Year," Recuperado el 30 de marzo de 2017 de http:/ / www.economist.com/news/leaders/21712136-which-country-improved-most-2016-our-country-year 


\section{ANEXO. PRODUCCIÓN LEGISLATIVA EN COLOMBIA, 2016}

Tabla 5. Producción legislativa en Colombia, 2016 - Leyes

\begin{tabular}{|c|c|c|c|}
\hline Proyecto & Fecha & Título & Tema \\
\hline $\begin{array}{l}\text { Ley } 1772 \text { del } 6 \text { de } \\
\text { enero de } 2016\end{array}$ & 06/01/2016 & $\begin{array}{l}\text { Por medio de la cual se declara patrimonio } \\
\text { inmaterial, cultural, artístico y folclórico de } \\
\text { la nación, el desfile el salsódromo que se } \\
\text { realiza dentro del marco de la feria de Cali, } \\
\text { y se dictan otras disposiciones. }\end{array}$ & $\begin{array}{l}\text { Celebraciones, } \\
\text { honores }\end{array}$ \\
\hline $\begin{array}{l}\text { Ley } 1773 \text { del } 6 \text { de } \\
\text { enero de } 2016\end{array}$ & $06 / 01 / 2016$ & $\begin{array}{l}\text { Por medio de la cual se crea el artículo } \\
116 a \text {, se modifican los artículos } 68 \text { a, 104, } \\
113,359 \text {, y } 374 \text { de la ley } 599 \text { de } 2000 \text { y se } \\
\text { modifica el artículo } 351 \text { de la ley } 906 \text { de } \\
2004 \text {. }\end{array}$ & Códigos \\
\hline $\begin{array}{l}\text { Ley } 1774 \text { del } 6 \text { de } \\
\text { enero de } 2016\end{array}$ & $06 / 01 / 2016$ & $\begin{array}{l}\text { Por medio de la cual se modifican el código } \\
\text { civil, la ley } 84 \text { de } 1989 \text {, el código penal, el } \\
\text { código de procedimiento penal y se dictan } \\
\text { otras disposiciones. }\end{array}$ & Códigos \\
\hline $\begin{array}{l}\text { Ley } 1775 \text { del } 29 \\
\text { de enero de } 2016\end{array}$ & $29 / 01 / 2016$ & $\begin{array}{l}\text { Por el cual se exceptúa la destinación espe- } \\
\text { cífica de que trata el parágrafo del artículo } \\
212 \text { de la ley } 115 \text { de } 1994 \text { de un área de } \\
\text { terreno denominada "La casona", donde } \\
\text { funcionó el antiguo colegio San José de } \\
\text { Alcántara de Guanenta. }\end{array}$ & $\begin{array}{l}\text { Celebraciones, } \\
\text { honores }\end{array}$ \\
\hline $\begin{array}{l}\text { Ley } 1776 \text { del } 29 \\
\text { de enero de } 2016\end{array}$ & $29 / 01 / 2016$ & $\begin{array}{l}\text { Por la cual se crean y se desarrollan las } \\
\text { Zonas de Interés de Desarrollo Rural, Eco- } \\
\text { nómico y Social, ZIDRES. }\end{array}$ & Economía \\
\hline $\begin{array}{l}\text { Ley } 1777 \text { del } 1 \text { de } \\
\text { febrero de } 2016\end{array}$ & $01 / 02 / 2016$ & $\begin{array}{l}\text { Por medio de la cual se definen y regulan } \\
\text { las cuentas abandonadas y se les asigna un } \\
\text { uso eficiente a estos recursos. }\end{array}$ & Economía \\
\hline $\begin{array}{l}\text { Ley } 1778 \text { del } 2 \text { de } \\
\text { febrero de } 2016\end{array}$ & $02 / 02 / 2016$ & $\begin{array}{l}\text { Por la cual se dictan normas sobre la res- } \\
\text { ponsabilidad de las personas jurídicas } \\
\text { por actos de corrupción transnacional y se } \\
\text { dictan otras disposiciones en materia de } \\
\text { lucha contra la corrupción. }\end{array}$ & Justicia \\
\hline $\begin{array}{l}\text { Ley } 1722 \text { del } 1 \text { de } \\
\text { marzo de } 2016\end{array}$ & $01 / 03 / 2016$ & $\begin{array}{l}\text { Por medio de la cual se aprueba el "acuerdo } \\
\text { de alcance parcial de naturaleza comercial } \\
\text { entre la República de Colombia y la Repú- } \\
\text { blica Bolivariana de Venezuela", suscrito en } \\
\text { caracas, República Bolivariana de Venezuela, } \\
\text { el } 28 \text { de noviembre de 2011, y sus seis anexos } \\
\text { con sus respectivos apéndices, suscritos en } \\
\text { Cartagena, República de Colombia, el } 15 \\
\text { de abril de 2012, así: Anexo I "tratamiento } \\
\text { arancelario preferencial". Anexo II "régimen } \\
\text { de origen". Anexo III "reglamentos técnicos, } \\
\text { evaluación de la conformidad y metrología". } \\
\text { Anexo IV "medidas sanitarias, zoosanitarias } \\
\text { y fitosanitarias". Anexo V "medidas de de- } \\
\text { fensa comercial y medida especial agrícola". } \\
\text { Anexo VI "mecanismo de solución de con- } \\
\text { troversias". }\end{array}$ & $\begin{array}{l}\text { Política } \\
\text { exterior }\end{array}$ \\
\hline
\end{tabular}




\begin{tabular}{|c|c|c|c|}
\hline Proyecto & Fecha & Título & Tema \\
\hline $\begin{array}{l}\text { Ley } 1779 \text { del } 11 \\
\text { de abril de } 2016\end{array}$ & $11 / 04 / 2016$ & $\begin{array}{l}\text { Por medio de la cual se modifica el artícu- } \\
\text { lo } 8^{\circ} \text { de la ley } 418 \text { de } 1997 \text {, prorrogada y } \\
\text { modificada por las leyes } 548 \text { de } 1999.782 \\
\text { de } 2002,1106 \text { de } 2006,1421 \text { de } 2010 \text { y } 1738 \\
\text { de } 2014 \text {. }\end{array}$ & Proceso de paz \\
\hline $\begin{array}{l}\text { Ley } 1780 \text { del } 2 \text { de } \\
\text { mayo de } 2016\end{array}$ & 02/05/2016 & $\begin{array}{l}\text { Por medio de la cual se promueve el } \\
\text { empleo y el emprendimiento juvenil, se } \\
\text { generan medidas para superar barreras de } \\
\text { acceso al mercado de trabajo y se dictan } \\
\text { otras disposiciones. }\end{array}$ & Política social \\
\hline $\begin{array}{l}\text { Ley } 1781 \text { del } 20 \\
\text { de mayo de } 2016\end{array}$ & $20 / 05 / 2016$ & $\begin{array}{l}\text { Por la cual se modifican los artículos } 15 \text { y } \\
16 \text { de la ley } 270 \text { de 1996, estatutaria de la } \\
\text { administración de justicia. }\end{array}$ & Justicia \\
\hline $\begin{array}{l}\text { Ley } 1782 \text { del } 20 \\
\text { de mayo de } 2016\end{array}$ & $20 / 05 / 2016$ & $\begin{array}{l}\text { Por medio de la cual se aprueba el "tratado } \\
\text { sobre el comercio de armas", adoptado por } \\
\text { la asamblea general de las naciones unidas } \\
\text { mediante resolución } 67 / 234 \text { b de } 2 \text { de abril } \\
\text { de } 2013 \text { y suscrito en la ciudad de Nueva } \\
\text { York, el } 24 \text { de septiembre de } 2013 \text {. }\end{array}$ & $\begin{array}{l}\text { Política } \\
\text { exterior }\end{array}$ \\
\hline $\begin{array}{l}\text { Ley } 1783 \text { del } 23 \\
\text { de mayo de } 2016\end{array}$ & $23 / 05 / 2016$ & $\begin{array}{l}\text { Por medio de la cual la nación le rinde ho- } \\
\text { menaje y exalta la vida del maestro Carlos } \\
\text { Gaviria Díaz, en reconocimiento a su labor } \\
\text { jurídica, académica, política y ética. }\end{array}$ & $\begin{array}{l}\text { Celebraciones, } \\
\text { honores }\end{array}$ \\
\hline $\begin{array}{l}\text { Ley } 1784 \text { del } 17 \\
\text { de junio de } 2016\end{array}$ & $17 / 06 / 2016$ & $\begin{array}{l}\text { Por medio de la cual la nación se asocia a la } \\
\text { conmemoración del bicentenario del sitio } \\
\text { de Cartagena de Indias, ciudad heroica y } \\
\text { exalta la memoria de los cartageneros que } \\
\text { resistieron } 105 \text { días. }\end{array}$ & $\begin{array}{l}\text { Celebraciones, } \\
\text { honores }\end{array}$ \\
\hline $\begin{array}{l}\text { Ley } 1785 \text { del } 21 \\
\text { de junio de } 2016\end{array}$ & $21 / 06 / 2016$ & $\begin{array}{l}\text { Por medio de la cual se establece la Red } \\
\text { para la Superación de la Pobreza Extrema } \\
\text { (RED UNIDOS) y se dictan otras disposi- } \\
\text { ciones. }\end{array}$ & Política social \\
\hline $\begin{array}{l}\text { Ley } 1786 \text { del } 1 \text { de } \\
\text { julio de } 2016\end{array}$ & $01 / 07 / 2016$ & $\begin{array}{l}\text { Por medio de la cual se modifican algunas } \\
\text { disposiciones de la ley } 1760 \text { de } 2015 \text {. }\end{array}$ & Códigos \\
\hline $\begin{array}{l}\text { Ley } 1787 \text { del } 6 \text { de } \\
\text { julio de } 2016\end{array}$ & $06 / 07 / 2016$ & $\begin{array}{l}\text { Por medio del cual se reglamenta el acto } \\
\text { legislativo } 2 \text { de } 2009 \text {. }\end{array}$ & Política social \\
\hline $\begin{array}{l}\text { Ley } 1788 \text { del } 7 \text { de } \\
\text { julio de } 2016\end{array}$ & $07 / 07 / 2016$ & $\begin{array}{l}\text { Por medio del cual se garantiza el acceso } \\
\text { en condiciones de universalidad al derecho } \\
\text { prestacional de pago de prima de servicios } \\
\text { para los trabajadores y trabajadoras do- } \\
\text { mésticos. }\end{array}$ & Política social \\
\hline $\begin{array}{l}\text { Ley } 1789 \text { del } 7 \text { de } \\
\text { julio de } 2016\end{array}$ & $07 / 07 / 2016$ & $\begin{array}{l}\text { Por la cual la nación y el Congreso de la } \\
\text { República se asocian y rinden homenaje al } \\
\text { Municipio de San Antonio, en el Departa- } \\
\text { mento de Tollma, con motivo de la conme- } \\
\text { moración de los cien años de su fundación } \\
\text { y se autorizan apropiaciones presupuesta- } \\
\text { les para la ejecución de obras de inversión } \\
\text { social. }\end{array}$ & $\begin{array}{l}\text { Celebraciones, } \\
\text { honores }\end{array}$ \\
\hline
\end{tabular}




\begin{tabular}{|c|c|c|c|}
\hline Proyecto & Fecha & Título & Tema \\
\hline $\begin{array}{l}\text { Ley } 1790 \text { del } 7 \text { de } \\
\text { julio de } 2016\end{array}$ & $07 / 07 / 2016$ & $\begin{array}{l}\text { Por medio de la cual se renueva la emisión } \\
\text { de la estampilla pro-Universidad Indus- } \\
\text { trial de Santander creada mediante ley } 85 \\
\text { de } 1993, \text { modificada parcialmente por la } \\
\text { ley } 1216 \text { de 2008, y se dictan otras disposi- } \\
\text { ciones. }\end{array}$ & $\begin{array}{l}\text { Celebraciones, } \\
\text { honores }\end{array}$ \\
\hline $\begin{array}{l}\text { Ley } 1791 \text { del } 7 \text { de } \\
\text { julio de } 2016\end{array}$ & $07 / 07 / 2016$ & $\begin{array}{l}\text { Por medio de la cual la nación se asocia a } \\
\text { la conmemoración de los } 145 \text { años de haber } \\
\text { sido erigido como municipio, Ciudad Boli- } \\
\text { var en el Departamento de Antioquia. }\end{array}$ & $\begin{array}{l}\text { Celebraciones, } \\
\text { honores }\end{array}$ \\
\hline $\begin{array}{l}\text { Ley } 1792 \text { del } 7 \text { de } \\
\text { julio de } 2016\end{array}$ & $07 / 07 / 2016$ & $\begin{array}{l}\text { Por medio de la cual se modifican algunos } \\
\text { artículos de los decretos ley } 1790 \text { y } 1791 \text { de } \\
\text { 2000, modificados por la ley } 1405 \text { de } 2010 \text { y } \\
\text { se dictan otras disposiciones. }\end{array}$ & $\begin{array}{l}\text { Seguridad, } \\
\text { defensa y } \\
\text { fuerza pública }\end{array}$ \\
\hline $\begin{array}{l}\text { Ley } 1793 \text { del } 7 \text { de } \\
\text { julio de } 2016\end{array}$ & $07 / 07 / 2016$ & $\begin{array}{l}\text { Por medio de la cual se dictan normas en } \\
\text { materia de costos de los servicios financie- } \\
\text { ros y se dictan otras disposiciones. }\end{array}$ & Economía \\
\hline $\begin{array}{l}\text { Ley } 1794 \text { del } 11 \\
\text { de julio de } 2016\end{array}$ & $11 / 07 / 2016$ & $\begin{array}{l}\text { Por medio de la cual se aprueba el "acuer- } \\
\text { do marco entre las Naciones Unidas y el } \\
\text { Gobierno de la República de Colombia } \\
\text { relativo a las contribuciones al sistema de } \\
\text { acuerdos de fuerzas de reserva de las na- } \\
\text { ciones unidas para las operaciones de man- } \\
\text { tenimiento de la paz", suscrito en la ciudad } \\
\text { de Nueva York el } 26 \text { de enero de } 2015 \text {. }\end{array}$ & Proceso de paz \\
\hline $\begin{array}{l}\text { Ley } 1795 \text { del } 12 \\
\text { de julio de } 2016\end{array}$ & $12 / 07 / 2016$ & $\begin{array}{l}\text { Por medio de la cual la nación se vincula } \\
\text { a la celebración de los } 60 \text { años de la Uni- } \\
\text { versidad del Tollma, se autorizan apro- } \\
\text { piaciones presupuestales y se dictan otras } \\
\text { disposiciones. }\end{array}$ & $\begin{array}{l}\text { Celebraciones, } \\
\text { honores }\end{array}$ \\
\hline $\begin{array}{l}\text { Ley } 1796 \text { del } 13 \\
\text { de julio de } 2016\end{array}$ & $13 / 07 / 2016$ & $\begin{array}{l}\text { Por la cual se establecen medidas enfo- } \\
\text { cadas a la protección del comprador de } \\
\text { vivienda, el incremento de la seguridad de } \\
\text { las edificaciones y el fortalecimiento de la } \\
\text { función pública que ejercen los curadores } \\
\text { urbanos, se asignan unas funciones a la } \\
\text { superintendencia de notariado y registro y } \\
\text { se dictan otras disposiciones. }\end{array}$ & Política social \\
\hline $\begin{array}{l}\text { Ley } 1797 \text { del } 13 \\
\text { de julio de } 2016\end{array}$ & $13 / 07 / 2016$ & $\begin{array}{l}\text { Por la cual se dictan disposiciones que } \\
\text { regulan la operación del sistema general de } \\
\text { seguridad social en salud y se dictan otras } \\
\text { disposiciones. }\end{array}$ & Política social \\
\hline $\begin{array}{l}\text { Ley } 1798 \text { del } 19 \\
\text { de julio de } 2016\end{array}$ & $19 / 07 / 2016$ & $\begin{array}{l}\text { Por medio de la cual la nación se vincula } \\
\text { a la celebración de los setenta (70) años de } \\
\text { existencia de la Universidad de Caldas y se } \\
\text { autoriza en su homenaje la financiación del } \\
\text { centro cultural universitario en sus etapas } \\
\text { LL y LLL. }\end{array}$ & $\begin{array}{l}\text { Celebraciones, } \\
\text { honores }\end{array}$ \\
\hline $\begin{array}{l}\text { Ley } 1799 \text { del } 25 \\
\text { de julio de } 2016\end{array}$ & $25 / 07 / 2016$ & $\begin{array}{l}\text { Por medio de la cual se prohíben los proce- } \\
\text { dimientos médicos y quirúrgicos estéticos } \\
\text { para menores de edad y se dictan otras } \\
\text { disposiciones. }\end{array}$ & Política social \\
\hline
\end{tabular}




\begin{tabular}{|c|c|c|c|}
\hline Proyecto & Fecha & Título & Tema \\
\hline $\begin{array}{l}\text { Ley } 1800 \text { del } 25 \\
\text { de julio de } 2016\end{array}$ & $25 / 07 / 2016$ & $\begin{array}{l}\text { Por medio de la cual la nación y el Congre- } \\
\text { so de la República se asocian a la conme- } \\
\text { moración de los } 150 \text { años del Municipio de } \\
\text { Pensilvania en el Departamento de Caldas } \\
\text { se le rinden honores y se dictan otras dis- } \\
\text { posiciones. }\end{array}$ & $\begin{array}{l}\text { Celebraciones, } \\
\text { honores }\end{array}$ \\
\hline $\begin{array}{l}\text { Ley } 1801 \text { del } 29 \\
\text { de julio de } 2016\end{array}$ & $29 / 07 / 2016$ & $\begin{array}{l}\text { Por la cual se expide el Código Nacional de } \\
\text { Policía y Convivencia. }\end{array}$ & Códigos \\
\hline $\begin{array}{l}\text { Ley } 1802 \text { del } 29 \\
\text { de julio de } 2016\end{array}$ & $29 / 07 / 2016$ & $\begin{array}{l}\text { Por medio de la cual se establece la tasa } \\
\text { real de } 0 \% \text { de intereses en los créditos } \\
\text { educativos otorgados por el Fondo Nacio- } \\
\text { nal del Ahorro para estudiantes de estratos } \\
1,2 \text { y } 3 \text {. }\end{array}$ & Política social \\
\hline $\begin{array}{l}\text { Ley } 1803 \text { del } 1 \text { de } \\
\text { agosto de } 2016\end{array}$ & $01 / 08 / 2016$ & $\begin{array}{l}\text { Por medio de la cual la nación se asocia a la } \\
\text { conmemoración de los cincuenta (50) años } \\
\text { de vida administrativa del Departamento } \\
\text { del Quindío, rinde público homenaje a sus } \\
\text { habitantes y se dictan otras disposiciones. }\end{array}$ & $\begin{array}{l}\text { Celebraciones, } \\
\text { honores }\end{array}$ \\
\hline $\begin{array}{l}\text { Ley } 1804 \text { del } 2 \text { de } \\
\text { agosto de } 2016\end{array}$ & $02 / 08 / 2016$ & $\begin{array}{l}\text { Por la cual se establece la política de Esta- } \\
\text { do para el desarrollo integral de la primera } \\
\text { infancia de cero a siempre y se dictan otras } \\
\text { disposiciones. }\end{array}$ & Política social \\
\hline $\begin{array}{l}\text { Ley } 1805 \text { del } 4 \text { de } \\
\text { agosto de } 2016\end{array}$ & $04 / 08 / 2016$ & $\begin{array}{l}\text { Por medio de la cual se modifican la ley } 73 \\
\text { de } 1988 \text { y la ley } 919 \text { de } 2004 \text { en materia de } \\
\text { donación de componentes anatómicos y se } \\
\text { dictan otras disposiciones. }\end{array}$ & Política social \\
\hline $\begin{array}{l}\text { Ley } 1806 \text { del } 24 \\
\text { de agosto de } 2016\end{array}$ & $24 / 08 / 2016$ & $\begin{array}{l}\text { Por medio de la cual se regula el plebiscito } \\
\text { para la refrendación del acuerdo final para } \\
\text { la terminación del conflicto y la construc- } \\
\text { ción de una paz estable y duradera. }\end{array}$ & Proceso de paz \\
\hline $\begin{array}{l}\text { Ley } 1807 \text { del } 1 \\
\text { de septiembre de } \\
2016\end{array}$ & $01 / 09 / 2016$ & $\begin{array}{l}\text { Por la cual se modifican parcialmente los } \\
\text { decretos-ley } 267 \text { y } 271 \text { de } 2000 \text { y se crea } \\
\text { la dependencia denominada “Centro de } \\
\text { Estudios Fiscales (CEF)" de la Contraloría } \\
\text { General de la República, se establecen sus } \\
\text { funciones y se dictan otras disposiciones. }\end{array}$ & Institucional \\
\hline $\begin{array}{l}\text { Ley } 1808 \text { del } 6 \\
\text { de septiembre de } \\
2016\end{array}$ & $06 / 09 / 2016$ & $\begin{array}{l}\text { Por medio de la cual la nación rinde ho- } \\
\text { nores a la memoria del periodista Enrique } \\
\text { Santos Castillo. }\end{array}$ & $\begin{array}{l}\text { Celebraciones, } \\
\text { honores }\end{array}$ \\
\hline $\begin{array}{l}\text { Ley } 1809 \text { del } 29 \\
\text { de septiembre de } \\
2016\end{array}$ & $29 / 09 / 2016$ & $\begin{array}{l}\text { Por medio de la cual se adiciona un pará- } \\
\text { grafo al artículo } 102 \text { de la ley } 50 \text { de } 1990 \text { y } \\
\text { se dictan otras disposiciones. }\end{array}$ & Política social \\
\hline $\begin{array}{l}\text { Ley } 1810 \text { del } 21 \\
\text { de octubre de } \\
2016\end{array}$ & $21 / 10 / 2016$ & $\begin{array}{l}\text { Por medio de la cual se conmemoran los } \\
200 \text { años del fallecimiento de Francisco José } \\
\text { de Caldas, y se dictan varias disposiciones } \\
\text { para celebrar dicha fecha. }\end{array}$ & $\begin{array}{l}\text { Celebraciones, } \\
\text { honores }\end{array}$ \\
\hline $\begin{array}{l}\text { Ley } 1811 \text { del } 21 \\
\text { de octubre de } \\
2016\end{array}$ & $21 / 10 / 2016$ & $\begin{array}{l}\text { Por la cual se otorgan incentivos para pro- } \\
\text { mover el uso de la bicicleta en el territorio } \\
\text { nacional y se modifica el código nacional } \\
\text { de tránsito. }\end{array}$ & Códigos \\
\hline
\end{tabular}




\begin{tabular}{|c|c|c|c|}
\hline Proyecto & Fecha & Título & Tema \\
\hline $\begin{array}{l}\text { Ley } 1812 \text { del } 27 \\
\text { de octubre de } \\
2016\end{array}$ & $27 / 10 / 2016$ & $\begin{array}{l}\text { Por medio de la cual se declara patrimonio } \\
\text { cultural inmaterial de la nación la celebra- } \\
\text { ción de la Semana Santa de la Parroquia } \\
\text { Santa Gertrudis La Magna de Envigado, } \\
\text { Antioquia y se dictan otras disposiciones. }\end{array}$ & $\begin{array}{l}\text { Celebraciones, } \\
\text { honores }\end{array}$ \\
\hline $\begin{array}{l}\text { Ley } 1813 \text { del } 9 \\
\text { de noviembre de } \\
2016\end{array}$ & $09 / 11 / 2016$ & $\begin{array}{l}\text { Por medio de la cual se modifica el artículo } \\
49 \text { de la ley } 191 \text { de } 1995 .\end{array}$ & $\begin{array}{l}\text { Celebraciones, } \\
\text { honores }\end{array}$ \\
\hline $\begin{array}{l}\text { Ley } 1814 \text { del } 25 \\
\text { de noviembre de } \\
2016\end{array}$ & $25 / 11 / 2016$ & $\begin{array}{l}\text { Por medio de la cual se adiciona y renueva } \\
\text { la estampilla Prodesarrollo Universidad } \\
\text { Surcolombiana contenida en la ley } 367 \text { de } \\
\text { 1997. }\end{array}$ & $\begin{array}{l}\text { Celebraciones, } \\
\text { honores }\end{array}$ \\
\hline $\begin{array}{l}\text { Ley } 1815 \text { del } 7 \text { de } \\
\text { diciembre de } 2016\end{array}$ & $07 / 12 / 2016$ & $\begin{array}{l}\text { Por la cual se decreta el presupuesto de } \\
\text { rentas y recursos de capital y ley de apro- } \\
\text { piaciones para la vigencia fiscal del } 1 \text { de } \\
\text { enero al } 31 \text { de diciembre de } 2017 \text {. }\end{array}$ & Presupuesto \\
\hline $\begin{array}{l}\text { Ley } 1816 \text { del } 19 \\
\text { de diciembre de } \\
2016\end{array}$ & $19 / 12 / 2016$ & $\begin{array}{l}\text { Por el cual se fija el régimen propio del } \\
\text { monopolio rentístico de licores destilados, } \\
\text { se modifica el impuesto al consumo de } \\
\text { licores, vinos, aperitivos y similares y se } \\
\text { dictan otras disposiciones. }\end{array}$ & Tributos \\
\hline $\begin{array}{l}\text { Ley } 1817 \text { del } 23 \\
\text { de diciembre de } \\
2016\end{array}$ & $23 / 12 / 2016$ & $\begin{array}{l}\text { Por medio de la cual la nación se asocia a } \\
\text { la conmemoración de los } 400 \text { años de fun- } \\
\text { dación de la Ciudad de Barbacoas, Depar- } \\
\text { tamento de Nariño. }\end{array}$ & $\begin{array}{l}\text { Celebraciones, } \\
\text { honores }\end{array}$ \\
\hline $\begin{array}{l}\text { Ley } 1818 \text { del } 28 \\
\text { de diciembre de } \\
2016\end{array}$ & $28 / 12 / 2016$ & $\begin{array}{l}\text { Por la cual la nación declara patrimonio } \\
\text { histórico y cultural al Municipio de Trini- } \\
\text { dad del Departamento de Casanare, exal- } \\
\text { tando su condición de cuartel general de la } \\
\text { campaña libertadora. }\end{array}$ & $\begin{array}{l}\text { Celebraciones, } \\
\text { honores }\end{array}$ \\
\hline $\begin{array}{l}\text { Ley } 1819 \text { del } 29 \\
\text { de diciembre de } \\
2016\end{array}$ & $29 / 12 / 2016$ & $\begin{array}{l}\text { Por medio de la cual se adopta una refor- } \\
\text { ma tributaria estructural, se fortalecen los } \\
\text { mecanismos para la lucha contra la evasión } \\
\text { y la elusión fiscal, y se dictan otras dispo- } \\
\text { siciones. }\end{array}$ & Tributos \\
\hline $\begin{array}{l}\text { Ley } 1820 \text { del } 30 \\
\text { de diciembre de } \\
2016\end{array}$ & $30 / 12 / 2016$ & $\begin{array}{l}\text { Por medio de la cual se dictan disposicio- } \\
\text { nes sobre amnistía, indulto y tratamientos } \\
\text { penales especiales y otras disposiciones. }\end{array}$ & Proceso de paz \\
\hline $\begin{array}{l}\text { Ley } 1821 \text { del } 30 \\
\text { de diciembre de } \\
2016\end{array}$ & $30 / 12 / 2016$ & $\begin{array}{l}\text { Por medio de la cual se modifica la edad } \\
\text { máxima para el retiro forzoso de las perso- } \\
\text { nas que desempeñan funciones públicas. }\end{array}$ & Institucional \\
\hline
\end{tabular}

Fuente: Presidencia de la República (2017) 
Tabla 6. Producción legislativa en Colombia, 2016 - Enmiendas constitucionales

\begin{tabular}{cclc}
\hline \multicolumn{1}{c}{ Proyecto } & Fecha & \multicolumn{1}{c}{ Título } & Tema \\
\hline & & $\begin{array}{l}\text { Por medio del cual se establecen instru- } \\
\text { mentos jurídicos para facilitar y asegurar }\end{array}$ & \\
Acto legislativo 01 & $07 / 07 / 2016$ & $\begin{array}{l}\text { la implementación y el desarrollo norma- } \\
\text { tivo del acuerdo final para la terminación } \\
\text { del 7 de julio de 2016 }\end{array}$ & proceso de \\
& & $\begin{array}{l}\text { del conflicto y la construcción de una paz } \\
\text { estable y duradera. }\end{array}$ & \\
& & & \\
\hline
\end{tabular}

Fuente: Presidencia de la República (2017)

Juan Carlos Rodríguez-Raga es Ph.D. en Ciencia Política de la University of Pittsburgh. Actualmente es profesor asociado del Departamento de Ciencia Política de la Universidad de los Andes (Bogotá) y codirector del Observatorio de la Democracia de este mismo departamento. Sus intereses de investigación incluyen las instituciones políticas (sistemas electorales, partidos y cortes) y la opinión pública, en perspectiva comparada. 
- 